OPEN ACCESS

Edited by: Albena Todorova Dinkova-Kostova, University of Dundee, United Kingdom

Reviewed by: Dionysios V. Chartoumpekis, University of Patras, Greece

Cheng Zhang,

Anhui Medical University, China

John Skoko,

University of Pittsburgh, United States

*Correspondence:

Miao Yan

yanmiao@csu.edu.cn

${ }^{t}$ These authors have contributed equally to this work

Specialty section: This article was submitted to

Signaling,

a section of the journal Frontiers in Cell and Developmental

Biology

Received: 05 November 2021 Accepted: 29 December 2021

Published: 02 February 2022

Citation:

Gao W, Guo L, Yang Y, Wang Y, Xia S, Gong H, Zhang B-K and Yan M (2022)

Dissecting the Crosstalk Between Nrf2 and NF- $k B$ Response Pathways in

Drug-Induced Toxicity.

Front. Cell Dev. Biol. 9:809952.

doi: 10.3389/fcell.2021.809952

\section{Dissecting the Crosstalk Between Nrf2 and NF-kB Response Pathways in Drug-Induced Toxicity}

\author{
Wen Gao ${ }^{1,2 \dagger}$, Lin Guo ${ }^{1 \dagger}$, Yan Yang ${ }^{1}$, Yu Wang ${ }^{1,2}$, Shuang Xia ${ }^{1}$, Hui Gong ${ }^{1}$, Bi-Kui Zhang ${ }^{1}$ and \\ Miao Yan $^{1 *}$ \\ ${ }^{1}$ Department of Pharmacy, The Second Xiangya Hospital, Central South University, Changsha, China, ${ }^{2}$ Xiangya School of \\ Medicine, Central South University, Changsha, China
}

Nrf2 and NF-kB are important regulators of the response to oxidative stress and inflammation in the body. Previous pharmacological and genetic studies have confirmed crosstalk between the two. The deficiency of Nrf2 elevates the expression of NF-kB, leading to increased production of inflammatory factors, while NF-kB can affect the expression of downstream target genes by regulating the transcription and activity of Nrf2. At the same time, many therapeutic drug-induced organ toxicities, including hepatotoxicity, nephrotoxicity, cardiotoxicity, pulmonary toxicity, dermal toxicity, and neurotoxicity, have received increasing attention from researchers in clinical practice. Drug-induced organ injury can destroy body function, reduce the patients' quality of life, and even threaten the lives of patients. Therefore, it is urgent to find protective drugs to ameliorate drug-induced injury. There is substantial evidence that protective medications can alleviate drug-induced organ toxicity by modulating both Nrf2 and NF-kB signaling pathways. Thus, it has become increasingly important to explore the crosstalk mechanism between Nrf2 and NF-kB in druginduced toxicity. In this review, we summarize the potential molecular mechanisms of Nrf2 and NF-kB pathways and the important effects on adverse effects including toxic reactions and look forward to finding protective drugs that can target the crosstalk between the two.

Keywords: Nrf2, NF-kB, crosstalk, drug-induced toxicity, toxic reactions

\section{THE OVERVIEW OF NUCLEAR FACTOR ERYTHROID (NF-E2)-RELATED FACTOR 2 (NRF2) AND NUCLEAR FACTOR-KAPPA B (NF-kB)}

\subsection{The Role of Nrf2 and Its Regulation}

When our body is continuously exposed to external stresses, it's easy to produce the excessive free radicals and reactive oxygen species (ROS) in the mitochondria, peroxisomes, and endoplasmic reticulum (ER), and downregulate endogenous antioxidants such as enzymes and antioxidant proteins (may be stress upregulated sometimes, but not enough to resist oxidative stress), thereby leading to damage of cellular components including proteins, DNA, and lipids (Tonelli et al., 2018). Antioxidant proteins are substances that can protect cells against free radical damage. However, supplementation of exogenous antioxidants can target oxidative stress by inhibiting the production of free radicals and ROS and bolstering the endogenous antioxidant capacity. Originally characterized as a master regulator of oxidative stress, the transcription factor Nrf2 continues to emerge as a critical mediator of cellular defense. Through the ongoing study on the Nrf2 pathway, more researchers find that Nrf2 is beneficial 

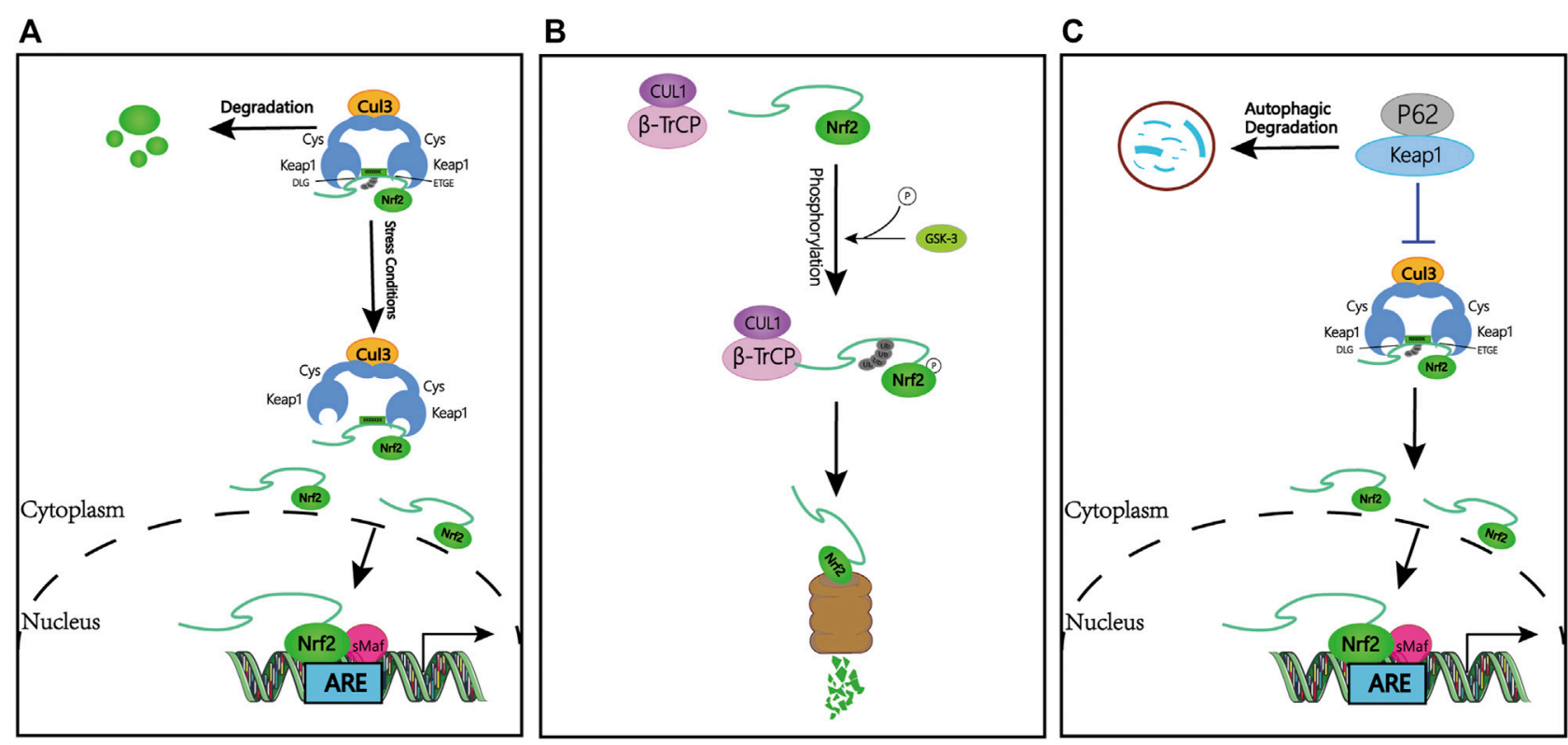

FIGURE 1 | Keap1-dependent and -independent regulation of Nrf2. (A) Keap1-dependent Nrf2 regulation. Under normal conditions, Nrf2 is sequestered in the cytoplasm by Keap1. Under oxidative stress, Nrf2 dissociates from Keap1, translocates to the nucleus and activates the ARE-gene battery. (B) Keap1-independent Nrf2 regulation. Phosphorylation of Nrf2 by GSK facilitates the recognition of Nrf2 by $\beta$-TrCP for CUL1-mediated ubiquitination and subsequent proteasome degradation. (C) P62-dependent Nrf2 regulation. p62 is sequestered with Keap1 and increased Nrf2 signaling. Abbreviations: Keap1, Kelch-like ECH-associated protein 1; Nrf2, Nuclear Factor Erythroid (NF-E2)-Related Factor 2; ARE, antioxidant response element; GSK-3, Glycogen synthase kinase 3; $\beta$-TrCP, $\beta$-transducin repeat-containing protein; Ub, ubiquitin.

for cell survival and proliferation from redox homeostasis, drug/xenobiotic metabolism to DNA repair (Dodson et al., 2019).

$\mathrm{Nrf} 2$ is a key transcription factor with a basic-region leucine zipper (bZIP) structure in the Cap-n-Collar (CNC) family, which controls many aspects of cell homeostasis in response to oxidative stress and toxic insults in various tissues and cells (Buendia et al., 2016; Skibinski et al., 2017; Dinkova-Kostova et al., 2018; Qu et al., 2020). It is a modular protein composed of seven Nrf2-ECH homology domains (Neh1-7) that perform different functions (Hayes and Dinkova-Kostova, 2014). Neh2 contains two important motifs known as DLG and ETGE, which are essential for the interaction between Nrf2 and its negative regulator Kelch-like ECH-associated protein 1 (Keap1) (Wang et al., 2014; Canning et al., 2015). The synthesized Nrf2 will translocate to the nucleus, and then form heterodimers with small musculoaponeurotic fibrosarcoma protein (MAF) K, G, and $F$. The heterodimer recognizes an enhancer sequence termed antioxidant response element (ARE) which is located in the regulatory regions of cellular defense enzyme genes. The target genes of Nrf2 encode the antioxidant proteins, metabolic enzymes, transporters, redox balancing factors, and glutathione-conjugated coenzyme (Ma, 2013; Hayes and Dinkova-Kostova, 2014; Wang et al., 2014; Canning et al., 2015; Cuadrado et al., 2018).

\subsection{Keap1-Dependent Nrf2 Regulation}

In the review of previous studies, the regulation of $\mathrm{Nrf} 2$ is considered a beneficial target for patients to release the disease. The best-characterized mechanism of $\mathrm{Nrf} 2$ regulation is the control of protein stabilization by the keap1-Cullin3 (Cul3)Ring-box protein 1 ( $\mathrm{Rbx} 1)$ complex, which acts as a protein level rheostat. Keap1 binds to Nrf2 via a specific amino acid sequence on its homodimeric $\mathrm{N}$-terminal domain, including siting with low (aspartate, leucine, and glycine; DLG) and high (glutamate, threonine, glycine, and glutamate; ETGE) affinity (hinge and latch hypothesis) (Cuadrado et al., 2018). Under the physiological state, Keap1 binds to Nrf2 and promotes ubiquitination and subsequent proteasomal degradation (Suzuki et al., 2013; Tonelli et al., 2018). Due to the short half-life of Nrf2 (10-30 min), Nrf2 remains at a very low basal level by sustained inhibition of Keap1. When stimulated by oxidative stress or Nrf2 activators, the thiol groups on cysteine residues in Keap1 are modified by electrophiles, and the function of Keap1 is diminished, ultimately resulting in the dissociation of $\mathrm{Nrf} 2$ from Keap1 and activation of Nrf2 and ARE genes (Hayes et al., 2010). Studies show that products of the Nrf2/ARE pathway, including NADPH, NAD (P) $\mathrm{H}$ quinone oxidoreductase 1 (NQO1), glutathione peroxidase, and heme oxygenase 1 (HO1 ), protect cells from various injuries and enhance body resistance through their activation (Ahmed et al., 2017) (Figure 1A).

\subsection{Keap1-independent Nrf2 Regulation}

Interestingly, Keap1-independent Nrf2 regulation is achieved through Glycogen synthase kinase 3 (GSK-3)/ $\beta$-transducin repeat-containing protein $(\beta-\operatorname{TrCP}), \beta-\operatorname{TrCP}$ is a substrate receptor for the $S$-phase kinase-associated protein 1 (Skp1)Cul1-Rbx1/Roc1 ubiquitin ligase complex that targets Nrf2 for ubiquitination and proteasomal degradation (Chowdhry et al., 

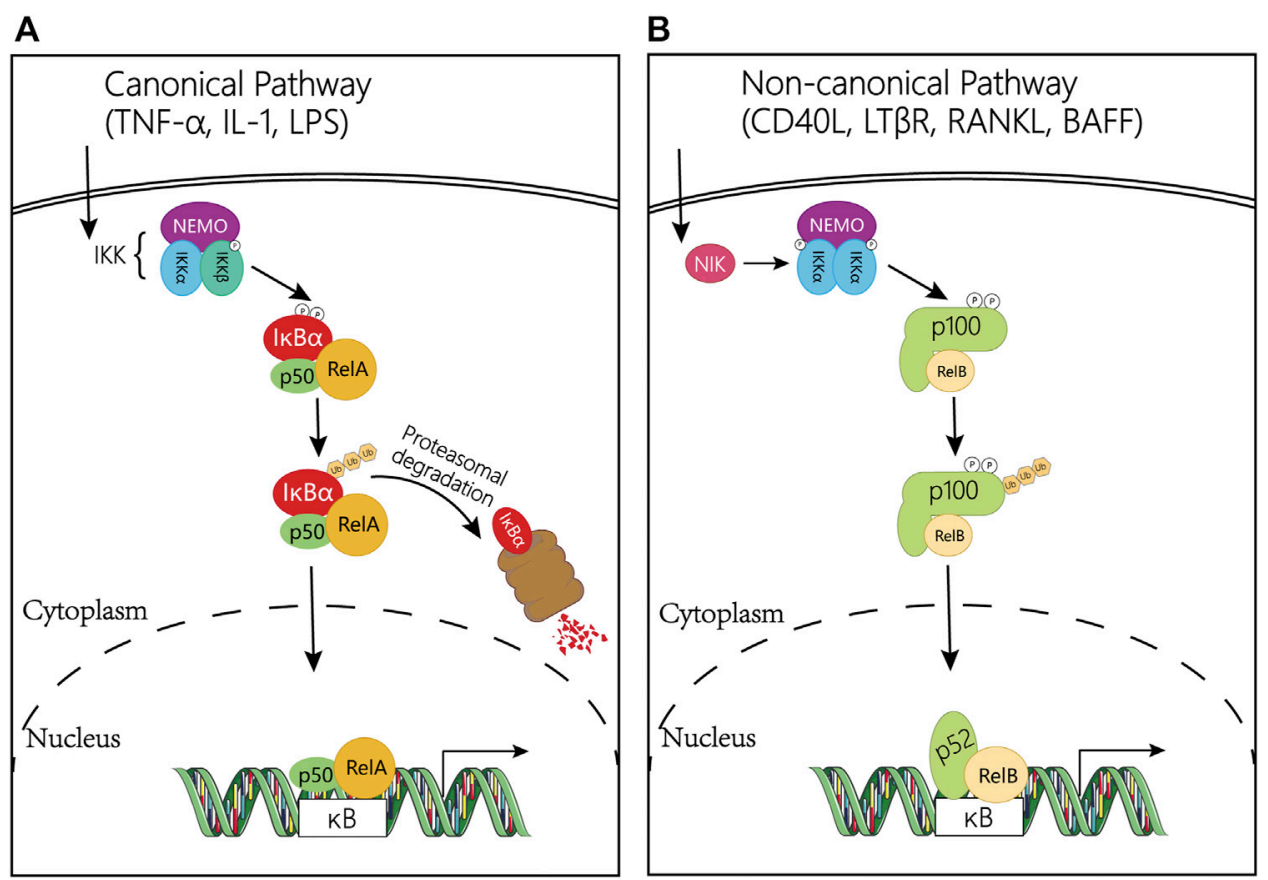

FIGURE 2 | Regulation mechanism diagram of NF-kB pathway. (A) Canonical NF-kB signaling pathway. The classical pathway is triggered by TNFa, IL-1, or LPS, and subsequently activates the $l_{\kappa} \mathrm{K}$ complex, which induces phosphorylation of $\mathrm{l}_{\kappa} \mathrm{B} \alpha$ and promotes its degradation. This leads to the release of the NF- $\mathrm{kB}$ heterodimer RelA/p50, which then translocates to the nucleus and induces the transcription of target genes. (B) Non-canonical NF- $\kappa B$ signaling pathway. This pathway is activated by CD40L, LT $\beta$ R, RANKL and BAFF gene, and mediated by NIK and the IкK complex containing two I kKa subunits, but not NEMO. In the non-canonical pathway, receptor binding leads to activation of the NF-kB-inducible kinase NIK, which phosphorylates and activates the lкKa complex, which in turn phosphorylates two serine residues adjacent to the $\mathrm{C}$-terminal lкB domain of the $\mathrm{p} 100$ ankyrin repeat, resulting in its partial proteolysis and release of the p52/RelB complex. Abbreviations: $\mathrm{NF}-\kappa \mathrm{B}$, Nuclear Factor-kappa B; TNFa: tumor necrosis factor $\alpha$; IL-1: interleukin-1; LPS: lipopolysaccharide; IkB, an inhibitor of $\kappa B$; IkK, IkB kinase; CD40L, CD40 ligand; RANKL, receptor activator of nuclear factor kappa-B ligand; LT $\beta R$, lymphotoxin beta; BAFF, B cell-activating factor; NIK, NF- $\kappa B$ inducing kinase.

2013). GSK-3 is responsible for phosphorylating a domain of Nrf2 (aspartate, serine, glycine, isoleucine, serine; DSGIS), creating a recognition motif for $\beta$-TrCP and then presenting Nrf2 to the Skp1-Cul1-Rbx1/Roc1 complex, finally leading to an alternative pathway for inhibition of Nrf2 (Rada et al., 2011; Cuadrado, 2015) (Figure 1B).

\subsection{P62-dependent Nrf2 кRegulation}

Additional pieces of evidence suggest that other regulators also may activate the Nrf2 pathway. P62, for example, sequesters Keap1 to its autophagic degradation and ultimately activates Nrf2dependent genes (Ma, 2013; Ahmed et al., 2017) (Figure 1C).

\section{THE NF-kB CELLULAR FUNCTION AND REGULATION}

The NF- $\kappa \mathrm{B}$ family, a regulator of $\kappa \mathrm{B}$ light chain expression in mature $B$ and plasma cells, regulates many genes involved in different cellular processes, such as cell differentiation, proliferation, development, and apoptosis. This family is composed of five structurally related members NF- $\kappa \mathrm{B} 1$ (also called p50), NF-kB2 (also called p52), RelA (also called p65), c-Rel, and RelB, encoded by NF- $\kappa \mathrm{B} 1, \mathrm{NF}-\kappa \mathrm{B} 2$, RELA, REL, and RELB, respectively. They share an N-terminal Rel homology domain (RHD) which is responsible for sequence-specific DNA binding, and homo- and hete-rodimerization (Hayden and Ghosh, 2008; Liu et al., 2017a; Peng et al., 2020). Based on the different mediators in the signaling cascade, the NF- $\kappa B$ signaling pathway can be categorized as either a canonical or noncanonical (alternative) pathway.

\subsection{Canonical Pathway}

Activation of the canonical NF- $\kappa \mathrm{B}$ pathway relies on its ability to bind with DNA controlled by the inhibitor of $\kappa \mathrm{B}(\mathrm{I} \kappa \mathrm{B})$. I $\mathrm{I} B$ protein, a subfamily of the large ankyrin repeat domain (ARD) containing superfamily, can bind NF- $\kappa$ B dimers to prevent the activation of NF- $\kappa \mathrm{B}$. The most common member of $\mathrm{I} \kappa \mathrm{B}$ in mediating the activation of the typical NF- $\kappa B$ pathway is $I \kappa B a$, which plays a central role in subsequent transcription (Hayden and Ghosh, 2008). Degradation of IKBa involves phosphorylation

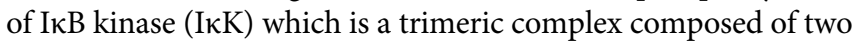
catalytic subunits, I $\kappa \mathrm{K} \alpha$ and $\mathrm{I} \kappa \mathrm{K} \beta$, and a regulatory subunit, I $\kappa \mathrm{K} \gamma$ (also named NF- $\kappa B$ essential modulator or NEMO) (Sun and Ley, 2008). In response to external stimulation, NF- $\kappa B$-bound I $\kappa B$ protein undergoes specific phosphorylation, ubiquitination, and proteasome-mediated proteolysis, allowing NF- $\mathrm{kB}$ to localize to the nucleus and bind to DNA (Hoffmann et al., 2006; Siggers et al., 2011; Wang et al., 2012; Zhao et al., 2014; Cildir et al., 2016) (Figure 2A). 


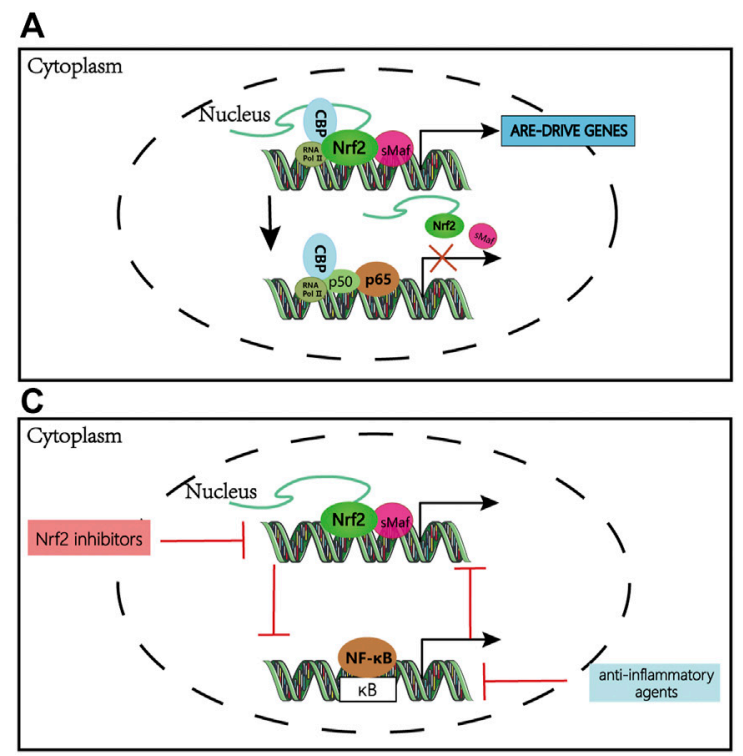

\section{B}

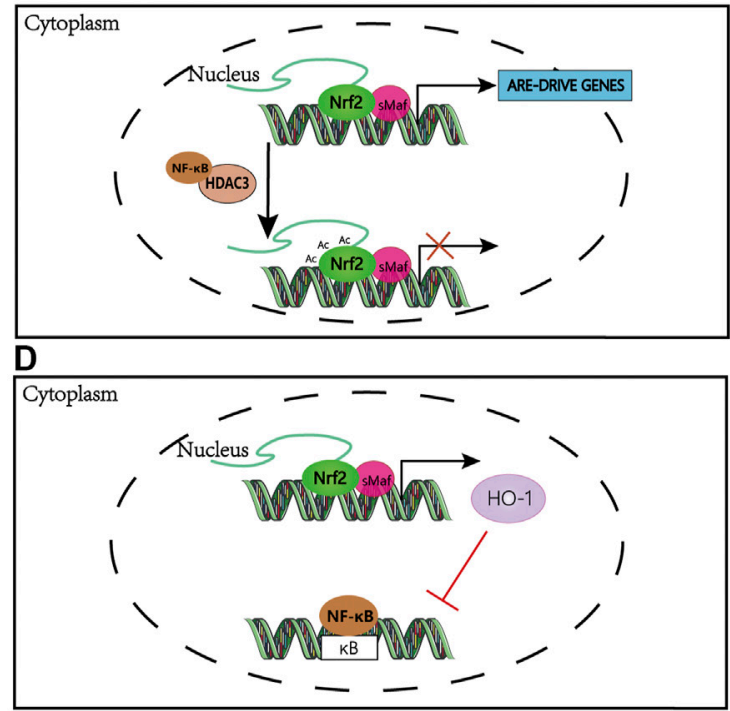

FIGURE 3 | The mechanism of crosstalk between Nrf2 and NF-kB pathways. (A) Nrf2 and NF-kB compete for CBP binding in the nucleus; binding of either transcription factor to CBP is dependent on the relative amount of translocated Nrf2 and NF-kB. (B) NF-kB-recruited HDAC3 deacetylates Nrf2 inhibiting AREdependent gene expression. (C) Nrf2 is indirectly activated by anti-inflammatory compounds that suppress NF-kB activity; likewise, NF-kB is indirectly activated by Nrf2 inhibitors. (D) HO-1, a downstream gene of Nrf2, can inhibit NF-kB transcription. Abbreviations: CBP, CREB-binding proteins; HDACs, histone deacetylases; Ac, deacetylation; HO-1, heme oxygenase 1.

\subsection{Non-Canonical Pathway}

On the contrary, activation of the non-canonical NF- $\mathrm{kB}$ pathway is slow and depend on a different set of protein synthesis, including CD40 ligand (CD40L), receptor activator of nuclear factor kappa-B ligand (RANKL), lymphotoxin beta (LT $\beta R$ ), and B cell-activating factor (BAFF) (Sun and Liu, 2011; Sun, 2012). In addition, the non-canonical NF- $\mathrm{KB}$ pathway relies on the processing of the NF- $\mathrm{KB} 2$ precursor protein, p100 rather than the degradation of IкBa. The NF- $\kappa B$ inducing kinase (NIK) phosphorylates and activates I $\mathrm{KKa}$, then synergistically regulating the phosphorylation of p100 (Senftleben et al., 2001; Sun, 2011; Sun, 2012). After that, this phosphorylation in turn induces the ubiquitination and proteasome-mediated partial degradation of p100 to generate p52. Meanwhile, the degradation processing of p100 not only forms p52 but also allows the nuclear translocation of the noncanonical NF- $\mathrm{kB}$ complex p52/RelB and then activates the NF- $\kappa B$ (Senftleben et al., 2001; Xiao et al., 2001; Sun, 2012; Cildir et al., 2016; Liu et al., 2017a). In the nucleus, p65 coordinates gene transcription by recruiting coactivators (e.g., CREB-binding proteins (CBP)) or corepressors (e.g., histone deacetylases (HDACs)) (Liu et al., 2008) (Figure 2B).

In the review of previous clinical and experimental studies, we find that tissues after external stimulation secrete cytokines including interleukin-1 (IL-1) and tumor necrosis factor-alpha (TNF- $\alpha$ ), of which TNF- $\alpha$ stimulates the activation of other inflammatory mediators (including NF- $\mathrm{KB}$ ), resulting in the release of inflammatory genes, and then leading to the persistence and deterioration of inflammation (Liu, 2005; Ju et al., 2020).

\section{THE INTERPLAY BETWEEN NRF2 AND NF-KB PATHWAYS}

The Nrf2 and NF-kB pathways co-regulate cellular responses to oxidative stress and inflammation. The underlying complex molecular mechanisms between these two important pathways remain to be further elucidated.

\subsection{NF-кB Inhibits the Nrf2 Pathway}

The NF-kB p65 subunit can directly inhibit the Nrf2 pathway at the transcriptional level. On the one hand, the NF- $\kappa B$ p 65 subunit competes with $\mathrm{Nrf2}$ for the CH1-KIX domain of the transcriptional co-activator $\mathrm{CBP}$, leading to the inactivation of the Nrf2 pathway (Figure 3A). On the other hand, NF- $\mathrm{kB}$ recruits HDAC3 by promoting the interaction of HDAC3 with CBP or MafK, causing local hypoacetylation and impeding Nrf2 signaling (Liu et al., 2008; Bellezza et al., 2010) (Figure 3B). Interestingly, a large number of anti-inflammatory agents can activate the Nrf2 pathway by interfering with NF- $\mathrm{kB}$ activation (Li et al., 2008; Minelli et al., 2012; Kim et al., 2013; Grottelli et al., 2016).

\subsection{Nrf2 Inhibits the NF-kB Pathway}

Nrf2 deficient mice subjected to severe head injury showed higher NF- $\kappa B$ activity compared to wild-type Nrf2 mice (Jin et al., 2008) (Figure 3C). A study explored the effect of Nrf2 on the activation of NF- $\mathrm{KB}$ and expression of inflammatory cytokine by using primary cultured astrocytes from Nrf2 wild-type (WT) or knockout (KO). The activity of NF- $\mathrm{kB}$ and the expression of inflammatory cytokines including TNF- $\alpha$, IL-1 $\beta$, interleukin- 6 (IL-6), and matrix metallopeptidase9 (MMP9) were upregulated 
in Nrf2 KO astrocytes and WT astrocytes, but the increase of which was more apparent in Nrf2 KO astrocytes. These results suggest that loss of Nrf2 may induce more aggressive inflammation by activating NF- $\kappa \mathrm{B}$ and downstream pro-inflammatory cytokines

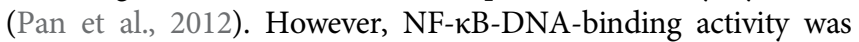
significantly inhibited in a diabetic mouse model with $\mathrm{Nrf} 2$ overexpression (Song et al., 2009). These studies suggest that we should also notice the negative regulation of NF- $\kappa \mathrm{B}$ by Nrf2.

There are results indicated that the Nrf2 gene has an NF- $\kappa B$ binding site which p65/p50 heterodimer is recruited, and I $\kappa \mathrm{K}-\beta$ plays a core role in NF- $\kappa \mathrm{B}$ signaling, contains an ETGE motif that enables it to bind to Keap1 (Lee et al., 2009; Jiang et al., 2013). Thereby, the selective recognition mechanism of Keap1 with I $\kappa K \beta$ or Nrf2 is vital to the crosstalk between NF- $\kappa \mathrm{B}$ and Nrf2 signaling. Besides, the Rho GTPase protein (RAC1) through I $\mathrm{B} B$ induces the increase of the transcriptional level of NF- $\kappa \mathrm{B}$, which in turn up-regulates the expression of Nrf2. However, Nrf2 deficiency induces $\mathrm{I} \kappa \mathrm{B} \alpha$ phosphorylation and subsequent degradation, increasing NF- $\mathrm{BB}$ levels and inducing inflammation (Cuadrado et al., 2014). Collectively, Nrf2 inhibits NF- $\kappa \mathrm{B}$ as a regulatory feedback loop. Moreover, much evidence indicates that Nrf2 downstream gene $\mathrm{HO}-1$, one of the centers of the crosstalk between $\mathrm{Nrf} 2$ and $\mathrm{NF}-\kappa \mathrm{B}$, plays a vital role in regulating inflammatory responses (Figure 3D). HO-1 may inhibit the nuclear translocation of the NF- $\kappa \mathrm{B}$ pathway to mediate inflammation via its end-products, i.e., carbon monoxide and bilirubin which have been reported to prevent the activation of NF- $\kappa B$ (Lee et al., 2003; Rushworth et al., 2008; Bellezza et al., 2012). Also, a study demonstrates that HO-1 inhibits LPSinduced TNF and IL-1 $\beta$ expression through suppression of NF- $\kappa B$ activation (Rushworth et al., 2008).

\section{TOXIC REACTIONS}

\subsection{Hepatotoxicity}

The liver is an important central organ for metabolism and detoxification in the human body and is susceptible to many factors, such as excessive alcohol consumption, hepatoviruses, various toxins, and drugs, leading to the development of liver diseases. Among them, drug-induced liver injury (DILI) and liver failure have high morbidity and mortality worldwide and it deserves further to explore the mechanisms and new targets against drug-induced hepatotoxicity (Andrade et al., 2019). Transcriptomic analysis of a variety of DILI compounds in primary hepatocytes showed that NF- $\kappa \mathrm{B}$ inhibition coincided with a strong Nrf2 stress response, which might sensitize hepatocytes to pro-apoptotic signaling cascades induced by endogenous cytotoxic proinflammatory cytokines and play a key role in the regulation of DILI (Herpers et al., 2016).

Nrf2 signaling pathway is an important way to regulate cellular oxidative stress, which plays an important role in DILI (Tong et al., 2006). Various regulatory factors are affecting the Nrf2 pathway. A study suggests that intestinal microorganisms modulate hepatic susceptibility to oxidative injury via the Nrf2 signaling pathway (Saeedi et al., 2020). Also, anti-inflammatory agents contribute a lot against hepatotoxicity.

\subsubsection{Acetaminophen (APAP)-Induced Hepatotoxicity}

Most DILI is caused by an intentional or unintentional overdose of APAP, which accounts for approximately $50 \%$ of all cases of liver injury in the United States (Larson et al., 2005). APAP, also known as N-acetyl-p-aminophenol, or paracetamol, is one of the most widely used over-the-counter analgesics and antipyretics and is considered safe at recommended therapeutic concentrations. However, excessive APAP can cause severe liver dysfunction, which threatens patients' lives (Buckley et al., 1999). Many studies have shown that Nrf2 KO mice are highly sensitive to APAP treatment compared to controls, and the cause of death is the inability to supply glutathione, a product downstream of Nrf2, promptly (Chan et al., 2001; Enomoto et al., 2001). Meanwhile, it has been reported that some protective agents could reduce mitochondrial oxidative stress, the inflammatory response by inhibiting signaling axes such as Keap1/Nrf2/HO-1, and thus protecting hepatocytes from APAP-induced injury (Wang et al., 2019a; Lv et al., 2019; Wu et al., 2019). Among them, corilagin and farrerol, the common hepatoprotective preconditioners, can effectively protect liver cells from APAP-induced acute liver failure (ALF) by activating $\mathrm{Nrf} 2$ or upregulating the AMPK/GSK3 $\beta-\mathrm{Nrf} 2$ signaling pathway, which in turn is involved in the prevention of hepatotoxicity (Wang et al., 2019a; Lv et al., 2019).

Meanwhile, the role of NF- $\kappa \mathrm{B}$ in hepatoprotection cannot be ignored. Maltol, a food-flavoring agent, was found to mitigate APAP-induced inflammatory responses by restraining the phosphorylation of $\mathrm{I} \kappa \mathrm{K} \alpha$, I $\kappa \mathrm{K} \beta$, and $\mathrm{I}-\kappa \mathrm{B} \alpha$ in a dosedependent manner, which exerted a significant liver protection effect (Wang et al., 2019b). And one study demonstrated that corilagin exerted protective effects against APAP-induced hepatotoxicity by inhibiting ERK/JNK mitogen-activated protein kinases (MAPK) and NF- $\mathrm{KB}$ signaling pathways (Liu et al., 2020). At the same time, a large number of hepatoprotective reagents (e.g., rutaecarpine, tovophyllin A) have been demonstrated to have significant therapeutic effects by upregulating Nrf2 transcript levels and inhibiting NF- $\mathrm{B}$ expression (Ibrahim et al., 2018; Choi et al., 2021). In addition, in APAP-induced hepatotoxicity models, the protein levels of Sirt1 are downregulated by IL $1 \beta / N F-\kappa B$ signaling, resulting in inflammation and oxidative stress (Rada et al., 2018). However, the limonin can alleviate APAP-induced hepatotoxicity by activating $\mathrm{Nrf} 2$ antioxidative signals and inhibiting NF- $\kappa \mathrm{B}$ inflammatory response via upregulating Sirt1 (Yang et al., 2020).

\subsubsection{Carbamazepine and Azathioprine-Induced Liver Injury}

Carbamazepine is a widely used antiepileptic drug that causes acute cholestatic injury and leads to hepatotoxicity. Using the live-cell imaging of the green fluorescent protein (GFP)-based reporter models for Nrf2 and NF- $\mathrm{KB}$ signaling, the researchers found that treatment with carbamazepine could cause DILI through an interconnected network of temporal changes in Nrf2 and NF-kB signaling, which influence each other and bring about phenotypes (slightly higher cell death) (Herpers et al., 2016). A study on the gene regulatory networks (GRNs) 
tells us that in azathioprine-induced liver injury, Nrf2 is widely activated and the activity of NF- $\kappa \mathrm{B}$ is inhibited. At the same time, the inferred network reveals the overlap of regulatory genes between $\mathrm{NF}-\mathrm{kB}$ and $\mathrm{Nrf2}$, demonstrating the relationship between NF-kB, Nrf2, and hepatotoxicity (Souza et al., 2017).

\subsubsection{Isoniazid (INH)-Induced Liver Injury}

Anti-tuberculosis drugs (e.g., INH)-induced hepatotoxicity $(\mathrm{ATDH})$ is a serious problem in tuberculosis treatment and hepatotoxicity management. INH reduced the phosphorylation of ERK1, then prevented Nrf2 translocation into the nucleus, and raised the cytosolic Nrf2 protein levels, thereby inhibiting Hep3B cell cytoprotection produced by the ARE response (Verma et al., 2015). Further studies revealed that INH increased ROS levels, promoted apoptosis, and decreased Nrf2 importer Karyopherin $\beta 1$ expression levels, thereby inhibiting the Nrf2 pathway (Verma et al., 2015; Verma et al., 2018). Accordingly, some protective candidates may target Nrf2 against INH-triggered hepatotoxicity or ALF. Sagittaria sagittifolia (SSP), a protectant against hepatotoxicity, increased the expression of Nrf2, glutamate-cysteine ligase, and HO-1, whereas that of keap1 was inhibited in INH-caused liver injury models (Wang et al., 2018). Interestingly, a new sight against hepatotoxicity may be to promote the stress activation of Nrf2 (Jia et al., 2019; Zhang et al., 2019). A study observed a significant increase in the mRNA expression of Nrf2 and the promotion of downstream factors such as HO-1 during INHinduced liver injury in zebrafish larvae (Jia et al., 2019). The Nrf2 signaling pathway was activated in the early stage of INHtriggered hepatotoxicity, as a stress compensatory mechanism, but just partially counteracting hepatotoxicity. Then when the liver injury was aggravated, the activation of the Nrf2 pathway was not enough to resist oxidative stress. Instead, a continuous accumulation of $\mathrm{Nrf} 2$ in the nucleus leads to more severe oxidative stress (Zhang et al., 2019).

Meanwhile, some results suggested that the expression of inflammatory mediators NF- $\mathrm{BB}$ was also upregulated in INHinduced liver injury. In rat models, pyrrolidine dithiocarbamate significantly reduced hepatic biochemical and histological damage by inhibiting the activation of NF- $\kappa B$ and oxidative stress caused by INH in a rat model demonstrating its hepatoprotective effect ( $\mathrm{He}$ et al., 2020). Other hepatoprotective agents have also been shown to exert the same therapeutic effect (Joseph Martin and Evan Prince, 2017). What's more, other drugs like gallic acid and quercetin attenuate $\mathrm{INH}$-induced liver injury by improving hepatic redox homeostasis through influence on Nrf2 and NF- $\kappa \mathrm{B}$ signaling cascades in Wistar rats (Sanjay et al., 2021a; Sanjay et al., 2021b). So in conclusion, many drugs protect against antituberculosis-induced liver injury by activating $\mathrm{Nrf} 2$ and blocking $\mathrm{NF}-\kappa \mathrm{B}$, and it is of greater clinical significance to investigate the interaction between $\mathrm{Nrf} 2$ and $\mathrm{NF}-\kappa \mathrm{B}$.

\subsubsection{Triptolide (TP)-Induced Liver Injury}

$\mathrm{TP}$ is one of the main biological activities and active ingredients of Tripterygium wilfordii Hook $F$, which has excellent immunoregulatory and anti-tumor activities and can be used to treat nephrotic syndrome, cancer, rheumatoid arthritis, and other autoimmune inflammatory diseases ( $\mathrm{Li}$ et al., 2014a; Li et al., 2015). However, the widespread use of TP remains limited by the narrow therapeutic window and hepatotoxicity ( $\mathrm{Li}$ et al., 2014a; Xi et al., 2017). To better understand the causes of TPinduced hepatotoxicity, we focused specifically on the role of Nrf2 and NF- $\mathrm{BB}$ in TP-induced hepatotoxicity, which also provides direction for future therapeutic targets. MiR155, a regulator of the Nrf2 antioxidant pathway, was significantly activated and then inhibited the activity of the Nrf2 pathway in TP-induced hepatotoxicity (Li et al., 2021a). TP indeed decreased the protein expressions of the Nrf2 pathway including HO-1, NQO1, and Nrf2 associated with the oxidative stress pathway (Zhou et al., 2020). And a study found that TP-induced oxidative stress and cell damage in HepG2 cells could be aggravated by Nrf2 knockdown or counteracted by overexpression of Nrf2 (Li et al., 2014b). In addition, treatment with sulforaphane (SFN), a typical Nrf2 agonist, attenuated TP-induced toxic effects such as liver dysfunction, structural damage, and glutathione depletion in mice by activating Nrf2 and its downstream targets (Li et al., 2014b). To illustrate a deeper mechanism, some scholars have found that catalpol (CAT), the main active ingredient of Rehmannia Glutinosa (RG), enhanced Nrf2 transcript expression by reversing $\mathrm{TP}$-induced Nrf2 transcriptional repression. The idea further proved that CAT induced UGT1A6, a phase II detoxifying enzyme of TP, through the Nrf2 pathway, thereby increasing TP metabolic conversion and reducing TP hepatotoxic effects (Fu et al., 2020). Meanwhile, another agent panax notoginseng saponins (PNS) significantly increased Nrf2 phosphorylation for relieving the potential inhibition of TP-induced Nrf2/ARE binding activity. These results highlight the necessity of the Nrf2/ARE pathway in the TP-triggered hepatotoxicity (Feng et al., 2019).

As an upstream regulator, Nrf2 not only regulates the oxidative stress response but also suppresses inflammation by regulating cytokine production and cross-talk with the NF- $\kappa B$ signaling pathway (Keleku-Lukwete et al., 2018). It has been previously reported that the alleviation of TP-induced hepatotoxicity was involved in the inactivation of the NF- $\kappa B$ pathway (Wei et al., 2017). Besides, TP treatment might disrupt immune homeostasis and induce liver hypersensitivity through the regulation of NF- $\kappa \mathrm{B}$-dependent pro-survival genes (Yuan et al., 2020). These shreds of evidence support the close correlation among unbalanced expression of $\mathrm{Nrf} 2, \mathrm{NK}-\kappa \mathrm{B}$, and hepatotoxicity.

\subsubsection{Polygonum Multiflorum (PM)-Induced Liver Injury}

PM, the root of P. multiflorum Thunb, has been used to treat various diseases, such as constipation, early graying of the hair, and hyperlipemia for several decades (Dong et al., 2014). The hepatotoxicity caused by PM treatment has attracted attention in recent years, which was initially considered to be non-toxic ( $Y u$ et al., 2011). As one of the main active components of PM, rhein could up-regulate the mRNA and protein levels of Nrf2, HO-1, and glutamate-cysteine ligase catalytic subunit (GCLC), downregulate the protein expression of NF- $\kappa \mathrm{B}, \mathrm{TNF}-\alpha$ and caspase-3, 
increase the survival rate of LO2 cells, decreasing the apoptosis rate and acting as a hepatoprotective drug (Li et al., 2021b). However, there is evidence to confirm that rhein has potential hepatorenal toxicity. A study clarified that immunological idiosyncratic hepatotoxicity induced by PM was associated with inhibition of the NF- $\kappa B$ pathway (Meng et al., 2017). We know that abnormal activation of the TLR4/NF- $\mathrm{BB}$ signaling pathway in response to external stimulation can trigger severe liver injury. Also, a large number of results support that PM regulates the Nrf2 pathway, but the specific toxicological mechanism remains to be explored in PM-induced liver injury models (Lin et al., 2018; Wang et al., 2020; Yu et al., 2020).

Overall, Nrf2 and NF- $\kappa$ B interact with each other to coordinate antioxidant and inflammatory responses. There is evidence indicating that $\mathrm{Nrf} 2 / \mathrm{HO}-1$ pathway and $\mathrm{NF}-\kappa \mathrm{B}$ pathway are involved in olaquindox (OLA)-induced hepatotoxicity. Meanwhile, curcumin can efficiently alleviate OLA-induced hepatotoxicity by further activating Nrf2/HO-1 pathway and inhibiting the p53 and NF- $\kappa B$ pathways to inhibit oxidative stress, apoptosis, and mitochondrial dysfunction ( $\mathrm{Li}$ et al., 2020a). In the previous study, teicoplanin (TIL) treatment significantly upregulated the relative hepatic expression of HSP70 and NF- $\mathrm{KB}$ mRNAs and blocked Nrf2/HO-1 mediated responses, indicating that TIL could induce oxidative stress and hepatotoxicity by blocking $\mathrm{Nrf2}$ mediated defense responses and increasing NF- $\kappa \mathrm{B}$ signaling pathways. On the other hand, the combination of astragalus polysaccharide (APS) and TIL improved the expression of the Nrf2 pathway, suggesting that the crosstalk between Nrf2 and NF-kB could be a new therapeutic target against hepatotoxicity (Farag et al., 2019). These pieces of evidence strongly complement our above discussion on the crosstalk of Nrf2 and NF- $\kappa \mathrm{B}$ in drug-induced hepatotoxicity, demonstrating that this connection may provide an insight into the development of future hepatoprotective agents.

\section{NEPHROTOXICITY}

Among the adverse effects, there is a great association between nephrotoxicity and the crosstalk between Nrf2 and NF- $\kappa$ B. Next, we will elaborate in-depth on typical drug-induced nephrotoxicity.

\subsection{Cisplatin-Induced Nephrotoxicity}

Cisplatin, a potent chemotherapeutic agent used for treating various types of solid organ tumors, is limited by its serious side effects in clinical application ( $\mathrm{Yu}$ et al., 2018; Deng et al., 2020). Cisplatin can cause an increase in the expression of NF- $\kappa B$ and TNF- $\alpha$ in the liver and kidney (Park et al., 2018). And abundant evidence suggests that antioxidant agents promote the anti-inflammatory effect by inhibiting the production of NF- $\kappa \mathrm{B}$ in the kidney even in the liver (Taghizadeh et al., 2020; Un et al., 2020). Celastrol, a potent chemotherapeutic agent, could ameliorate cisplatin-induced nephrotoxicity through suppressing $\mathrm{NF}-\mathrm{\kappa B}$ and protecting mitochondrial function in vitro and in vivo (Yu et al., 2018). Similarly, polysulfide and
H2S could afford protection against cisplatin-caused nephrotoxicity via persulfidating STAT3 and I $\mathrm{IK} \beta$ and inhibiting NF- $\kappa$ B-mediated inflammatory cascade (Sun et al., 2020). In addition, Nrf2 is a key molecule involved in targeting specific proteins in the NF- $\mathrm{BB}$ pathway and may be implicated in inflammatory regulation (Deng et al., 2020). Cisplatin can down-regulate Nrf2 and HO-1 while upregulating inflammatory factors. And embelin, an antiinflammatory drug, can alleviate cisplatin-induced nephrotoxicity by activating the signaling pathway of $\mathrm{Nrf2} /$ HO-1 and impeding NF- $\kappa$ B (Qin et al., 2019). Some studies have found that vinorelbine protects against cisplatin-induced acute kidney injury (AKI) by activating Nrf2/HO-1 signaling pathway and hindering TLR4-IFN- $\gamma$-CD44 cell inflammatory cascade when investigating the molecular mechanism of renal protection against nephrotoxicity (El-Sayed et al., 2021). Accumulating evidence suggests that the antioxidant mechanism protecting against enucleation-induced nephrotoxicity involves the $\mathrm{Nrf} 2 / \mathrm{HO}-1$ signaling pathway (Younis et al., 2020).

Some scholars have found that in the cisplatin-induced AKI mice, the C. cicadae mycelium extract regulated the inflammatory response by inhibiting renal pathological changes, inflammatory cell infiltration, and the release of a variety of inflammatory cytokines such as TNF- $\alpha$, IL- $1 \beta$, and IL- 6 . Further data revealed that the $\mathrm{C}$. cicadae mycelium extract exerted potent detoxifying effects by inhibiting TLR4/NF- $\kappa \mathrm{B} / \mathrm{MAPK}$ and regulating the $\mathrm{HO}-$ $1 / \mathrm{Nrf2}$ signaling pathway while regulating autophagy and inhibiting apoptosis to alleviate renal injury (Deng et al., 2020). Furthermore, thymoquinone and curcumin combination also prevented cisplatin-induced kidney injury by attenuating NF- $\mathrm{KB}, \mathrm{KIM}-1$ and ameliorating $\mathrm{Nrf} 2 / \mathrm{HO}-1$ signaling (Al Fayi et al., 2020).

\subsection{Aristolochic Acid (AA)-Induced Nephrotoxicity}

Ingestion of Chinese herbal medicines containing AA can induce aristolochic acid nephropathy (AAN) which is a rapidly progressive tubulointerstitial disease (Vanherweghem et al., 1993). Earlier evidence supports that AA-induced AKI is associated with impaired activation of $\mathrm{Nrf} 2$ and its downstream target gene expression (Wu et al., 2014). Therefore, we boldly guess that nephrotoxicity can be alleviated by activating the Nrf2 signaling pathway and increasing the expression of downstream target genes. Unsurprisingly, enhancement of the Nrf2 signaling pathway ameliorated AA-induced tubular epithelial cell injury, while down-regulation of the Nrf2 signaling pathway caused the opposite results, fully demonstrating that Nrf2 plays an important role in the AA-induced nephrotoxicity (Huang et al., 2020). Furthermore, a study has found that methylbarbadenolone (BARD), an antioxidant modulator, could play a renoprotective role through the Nrf2 signaling pathway (Song et al., 2019). It significantly ameliorated AAinduced tubular necrosis and interstitial fibrosis by up-regulating the renal expression of Nrf2 and Smad7 (Song et al., 2019). 
In addition, NF- $\kappa \mathrm{B}$ is also significantly activated in AAinduced nephropathy (Zhao et al., 2015). Notably, AA exhibited cytotoxicity in a dose-dependent and time-dependent manner. At a safe dose, AA could significantly inhibit the activity of NF- $\kappa B$ in HK2 cells and show the pharmacological effect (Chen et al., 2010). However, in the AA-induced renal injury model, the expression of NF- $\mathrm{kB}$ was abnormally elevated, suggesting that the dual effects of NF- $\kappa B$ may be one reason for the different properties of AA on the kidney. Demonstrating our idea from the reverse aspect, the Chinese herb Sedum sarmentosum extract (SSB) reduced the activity of the NF- $\kappa \mathrm{B}$ signaling pathway when exerting renoprotective effects (Bai et al., 2014). Also, AA may be involved in the alteration of matrix homeostasis during renal fibrosis in vivo, including the imbalance of extracellular matrix (ECM) accumulation and matrix metalloproteinase (MMP) activation involving NF- $\kappa B$ (Tsai et al., 2014). Therefore, we can improve renal fibrosis by regulating the activity of the NF- $\kappa \mathrm{B}$ pathway, and providing new ideas for drug therapy of nephropathy (Tsai et al., 2014). All the above evidence suggests that in AA-induced nephrotoxicity, NF- $\kappa \mathrm{B}$ is a network core molecule that can modulate the immune and inflammatory responses that occur in the kidney.

\subsection{Contrast-Induced (CI) AKI}

As the third most common cause of AKI, the use of contrast agents and contrast-induced nephropathy (CIN) have become the focus of global public health attention (Yang et al., 2015). This event has been reported to occur in about $30 \%$ of patients receiving invasive image examinations and is strongly associated with a high risk of death, long hospital stays, and adverse outcomes such as a high risk of chronic kidney disease (Nash et al., 2002; Finn, 2006). In exploring possible therapeutic options for CIN, researchers have found that a renal protective drug could increase the activation of the Nrf2 antioxidant defense pathway (Khaleel et al., 2017). Further mechanism elaboration, the protective effect against CIN could be exerted through Nrf2/ Sirt3/SOD2 or Nrf2/HO-1 pathways (Khaleel et al., 2019; Zhou Q et al., 2019). Moreover, recent studies have found that STC1, a conserved glycoprotein with anti-apoptosis and function, could target Nrf2 to reduce kidney injury and provide a promising preventive target for the treatment of CI-AKI (Zhao et al., 2020).

Similarly, NF- $\kappa \mathrm{B}$ is aberrantly activated in CIN, but NF- $\kappa \mathrm{B}$ expression is decreased and renal tissue hyalinization, hemorrhagic casts, and necrosis are reduced after infliximab treatment (Saritemur et al., 2015). And TLR4/Myd88/NF- $\kappa B$ is also involved in the protective pathway (Yue et al., 2017). In addition, a study has revealed that overexpression of miR429 inhibits the NF- $\mathrm{KB}$ signaling pathway by targeting programmed cell death 4 (PDCD4) to reduce apoptosis and improve cell viability in a CI-AKI cell model (Niu et al., 2021).

\subsection{Gentamicin (GM)-Induced AKI}

GM is an aminoglycoside antibiotic commonly used to treat acute gram-negative bacterial diseases. However, at least $30 \%$ of patients who received GM for more than 7 days had an increased risk of AKI (Cuzzocrea et al., 2002). Melatonin $(\mathrm{MT})$ restores antioxidant enzyme activity and blocks NF- $\kappa \mathrm{B}$ and nitric oxide synthase (iNOS) activation in rat kidneys, thereby preventing GM-induced nephrotoxicity, and these experimental results confirm that MT protects the kidney as a potent antioxidant (Lee et al., 2012). Besides, GM was found to promote nuclear NF- $\mathrm{KB}$ (p65) expression and inflammatory cytokine cytokines (TNF- $\alpha$ and IL- 6 ) and upregulate NF- $\kappa \mathrm{B}$ DNA-binding activity in kidney cells. In contrast, nephroprotective drugs can attenuate the abnormity of these genes, thereby reducing the degree of histological damage and neutrophil cell infiltration in renal tubules (Ansari et al., 2016). Also, NF- $\kappa B$ inhibitors have the same effect (Tugcu et al., 2006). On the other side, both Keap1/Nrf2/ARE and PKC/Nrf2 antioxidant pathways can be activated to enhance the attenuation function of the kidney (Arjinajarn et al., 2016; Ali et al., 2021). In addition, Nrf2 and NF- $\mathrm{BB}$ pathways can be simultaneously regulated in GM-induced nephrotoxicity models, and which provides direct evidence between the crosstalk of $\mathrm{Nrf} 2$ and $\mathrm{NF}-\kappa \mathrm{B}$ and drug-induced toxicity (Kalayarasan et al., 2009; Mahmoud, 2017). In future therapeutic strategies, increasing the nuclear immunoreactivity of Nrf 2 and decreasing that of NF- $\kappa \mathrm{B}$ could be taken into account.

\subsection{Methotrexate (MTX)-Induced AKI}

MTX is an anti-proliferative folic acid antagonist widely used in clinical treatment for cancers and chronic inflammatory diseases, but its nephrotoxicity limits its use. Some researchers have found that MTX-induced nephrotoxicity could be attenuated by vincamine, playing a protective role in the already peripheral and central nervous systems of the kidney. The therapeutic effect of vincamine against MTX-induced renal injury was through inhibiting oxidative stress while decreasing the expression of the NF- $\kappa \mathrm{B}$ pathway by increasing the expression of Nrf2 and HO-1 (Shalaby et al., 2019). And some other nephroprotective agents, such as chicoric acid, umbelliferone and berberine, also exert their protective effects by the same mechanism (Hassanein et al., 2018; Abd El-Twab et al., 2019; Hassanein et al., 2019). Indeed, the importance regarding the modulation of NF- $\mathrm{BB}$ and Nrf2 pathway activity in MTX-induced AKI has been efficiently shown (Sherif et al., 2020), especially Nrf2. Activation of the Nrf2/HO-1 signaling pathway can effectively protect kidney structure from destruction, while various factors lead to the elevated activity of $\mathrm{Nrf} / \mathrm{HO}-1$, such as the expression level of miR145-5p which directly targets Sirt5 (Mahmoud et al., 2018; Aladaileh et al., 2019; Li et al., 2021c).

Let us pay attention to whether, the body affected by nephropathy also causes further nephrotoxicity by breaking the balanced relationship between the two pathways, in addition to nephrotoxicity caused by the crosstalk of Nrf2 and $\mathrm{NF}-\kappa \mathrm{B}$. When exploring whether diabetes aggravates I/R-induced AKI in rats, some results have shown that diabetes aggravated oxidative stress, inflammatory response, and apoptosis after renal I/R by enhancing TLR4/NF- $\kappa \mathrm{B}$ signaling and blocking the Nrf2/ HO-1 pathway. However, pretreatment with tBHQ (an Nrf2 agonist) inhibited NF- $\mathrm{BB}$ signaling and enhanced the function of anti-apoptosis (Gong et al., 2019). These results indicate that the crosstalk between Nrf2 and NF- $\mathrm{KB}$ is involved in the development of nephrotoxicity. 


\section{CARDIOTOXICITY}

As same as nephrotoxicity, there are lots of results that have shown a tight association between the crosstalk and drug-induced cardiotoxicity.

\subsection{Doxorubicin (DOX)-Induced Cardiotoxicity}

DOX, an anthracycline antibiotic, has been widely used to treat both solid and hematologic malignancies (Octavia et al., 2012). However, DOX can lead to myocardial cell loss, mitochondrial dysfunction, myelofibrosis, and congestive heart failure in the body, triggering cardiotoxicity after long-term use (Eschenhagen et al., 2011; Brown et al., 2015; Varga et al., 2015; Chung and Youn, 2016; Zagar et al., 2016). DOX-induced cardiotoxicity is mediated by ROS production and the Nrf2/ARE pathway. Natural compounds (NCs), such as Asiatic acid, a-linolenic acid, apigenin, and $\beta$-LAPachone, were confirmed to ameliorate DOX-induced cardiac injury by activating $\mathrm{Nrf} 2$ in different pathways (Yarmohammadi et al., 2021). For example, cardamonin (CAR), a flavone found in Alpinia plants, can reduce the NF- $\kappa \mathrm{B}$ signaling pathway and improve Nrf2 signaling to suppress oxidative stress, apoptosis, and inflammatory response, ameliorating DOX-induced cardiotoxicity (Qi et al., 2020). And previous studies have shown that miR140-5p increases DOXinduced myocardial oxidative damage by inhibiting Nrf2 and Sirt2 signaling pathways (Zhao et al., 2018). Conversely, miR200a protects against DOX-induced cardiotoxicity by activating the Nrf2 signaling pathway (Hu X et al., 2019). This suggests that microRNA acts as a regulatory medium to modulate the Nrf2 pathway to aggravate or ameliorate DOX-induced cardiotoxicity.

Notably, DOX induced the expression of NF- $\mathrm{kB}$ p65 and caspase-3 in myocardial nuclei in a DOX-induced cardiotoxicity model. Interestingly, NF- $\mathrm{B}$ p 65 and caspase-3 were significantly inhibited by trifluoperazine, a strong calmodulin antagonist, suggesting that the cardioprotective effect conferred by trifluoperazine involves inhibition of NF$\kappa \mathrm{B}$ and apoptosis. Furthermore, biochemical and histopathological examinations revealed that trifluoperazine ameliorated DOX-induced renal and hepatic injury both functionally and structurally (Goda et al., 2021). Similarly, another drug geraniol may function as a potential activator of Nrf2, subsequently improve Nrf2 dependent antioxidant signaling, reduce apoptosis, and attenuate inflammatory responses (Younis et al., 2021). Antioxidant drugs may be a potential therapeutic target to prevent the development of DOXinduced cardiotoxicity by inhibiting oxidative stress and NF- $\kappa \mathrm{B}$ pathways (Sahu et al., 2019; Xu et al., 2020).

The study suggests the necessity and importance of discussing the crosstalk between Nrf2 and NF- $\mathrm{BB}$ in drug-induced cardiotoxicity. On top of that, among the organ injuries, the rising morbidity and mortality of highlighting cardiovascular diseases (CVDs) make cardiac injury attract people's attention. Some studies have found that aging is a major risk factor for CVDs (Niccoli and Partridge, 2012; Jaul and Barron, 2017; Franceschi et al., 2018). Under physiological conditions, Nrf2 and NF- $\kappa \mathrm{B}$ are degraded via the proteasome without cardiotoxicity. When aging disrupts the balance of Nrf2 and $\mathrm{NF}-\kappa \mathrm{B}$, it can increase ROS/RNS and activate inflammatory signaling pathways, thereby damaging cellular components and leading to cardiac injury (de Almeida et al., 2020). Also, the ability of adhesion, proliferation, migration, and formation of capillarylike structures is compromised by dysfunction of Nrf2 signaling and it revealed Nrf2 might be a prominent target to release angiogenesis and microvascular rarefaction (Valcarcel-Ares et al., 2012). It has earlier been reported that the NF- $\kappa B$ p65 subunit inhibits the Nrf2/ARE pathway at the transcriptional level (Liu et al., 2008), so there may be crosstalk between NF- $\kappa B$ and Nrf2 in the decrease of Nrf2 expression.

\section{PULMONARY TOXICITY}

\subsection{Bleomycin (BLM)-Induced Lung Injury}

BLM, a glycopeptide antibiotic, is an effective antineoplastic agent commonly used to treat breast, ovarian, lung, and different types of leukemia (Levine et al., 1985). However, the effective use of BLM in chemotherapy remains limited, as it precipitates dose-dependent interstitial pneumonia, resulting in pulmonary fibrosis in at least $10 \%$ of individuals treated with BLM, ultimately leading to irreversible lung structural damage (Yen et al., 2005; Di Paola et al., 2016). BLM aggravates pulmonary inflammation and apoptosis by up-regulating the expression of NF- $\kappa \mathrm{B}$ signaling pathway and apoptosis regulator caspase-3, and substantially reducing the activity of antioxidant enzymes in a rat model of BLM-induced pulmonary fibrosis (Beigh et al., 2017). Furthermore, NF- $\kappa B$ p105 and NF- $\kappa$ B p65 are involved in the progression of acute lung injury (ALI) and play important roles in tumorigenesis, inflammation, and immunity, which are important for elucidating therapeutic strategies for ALI (Shaikh and Prabhakar Bhandary, 2020). Juglans regia extract can inhibit NF-kB activation and reduce the expression of proinflammatory biomarkers such as cyclooxygenase 2 (COX-2) and iNOS to slow down pulmonary fibrosis. The protective effect is to reduce BLMinduced oxidative stress and pulmonary inflammation by regulating the inflammatory response of rat alveolar macrophages (Beigh et al., 2017). Meanwhile, the involvement of the Nrf2 pathway in the process of BLM-induced lung injury has also been mentioned (Liu et al., 2017b). It has become clear that artemisinin, a novel Nrf2 activator, activates the Nrf2 pathway by reducing Nrf2 ubiquitination and improving its stability (Chen et al., 2016). On the other hand, the subsequent antioxidant protection can be achieved by regulating the $\mathrm{Nrf} 2 / \mathrm{HO}-1$ signaling pathway (Ahmad et al., 2020).

The hepatoprotective effects of NF- $\mathrm{BB}$ and Nrf2 have been demonstrated in BLM-treated animals. It is curious whether there are potential interaction mechanisms between the two genes that together regulate antioxidant levels to protect against lung injury? Earlier studies have shown that NF- $\mathrm{B}$ and Nrf2 expression levels are simultaneously regulated by hepatoprotective drugs. In BLM-treated pneumonocytes, salidroside inhibits I $\mathrm{BBa}$ phosphorylation and the nuclear accumulation of NF- $\kappa B$ p65 while activating Nrf2-antioxidant signaling (Tang et al., 2016). In 
addition, hesperidin attenuates BLM-induced lung toxicity by inhibiting the I $\kappa \mathrm{B} \alpha / \mathrm{NF}-\kappa \mathrm{B}$ pathway, which in turn improves the regulation of oxidative inflammatory markers (Nrf2 and HO-1) and pro-inflammatory markers (TNF- $\alpha$, IL- $1 \beta$, and IL-6) to reduce collagen deposition during pulmonary fibrosis (Zhou $Z$ et al., 2019). Besides, treatment of Glycyl-L-histidyl-L-lysine (GHK)-Cu complexes modulates the Nrf2 and NF- $\mathrm{BB}$ pathways, and Smad2/3 phosphorylation partially prevents the development of epithelial-mesenchymal transition (EMT) and has a protective effect against BLM-induced inflammation and oxidative stress. However, the specific interaction mechanism between the two remains to be elucidated (Ma et al., 2020). A study revealed that the activation of NF- $\mathrm{BB}$ and Nrf2 pathways played opposite roles in lung injury, respectively. And in the hepatoprotective mechanism, the activity of Nrf2 increases, which has a potential inhibitory effect on the NF- $\mathrm{BB}$ pathway, plays a better protective effect (Kang et al., 2020).

\section{DERMAL TOXICITY}

Psoriasis is a skin disease mediated by immune response disorders, with a prevalence of $2-3 \%$ in the world's population (Brück et al., 2018; Lee et al., 2020). And the patients are suffered from skin itching, pain, seriously affecting the quality of life of patients (Nestle et al., 2009; Boehncke and Schön, 2015). While the etiology of psoriasis remains to be fully elucidated, studies are revealing the crosstalk between Nrf2 and NF- $\kappa \mathrm{B}$ in psoriasis (Sangaraju et al., 2021).

\subsection{Imiquimod (IMQ)- Induced Psoriasis}

The results from IMQ-induced psoriasis models in vitro confirm the involvement of NF- $\kappa \mathrm{B} 1$ in psoriasis pathogenesis through mediated T cell (Th1 and Th17) activation (Zhou et al., 2018). The role of Nrf2 and NF- $\kappa \mathrm{B}$ pathways in psoriasis has been previously documented, but the exact interaction between the two has not been elucidated (Li et al., 2020b; Sangaraju et al., 2021). Tussilagonone (TGN), a sesquiterpenoid isolated from Tussilagofarfara, has been used to treat IMQ-induced psoriasis-like dermatitis mice when further exploring transcription factors associated with psoriasis pathogenesis. As a potent Nrf2 activator, TGN can significantly activate the Nrf2 pathway and induce the expression of its downstream target gene HO-1 by inhibiting NF- $\mathrm{kB}$ and STAT3. In turn, activation of Nrf2/HO-1 by TGN also inhibits activation of NF- $\kappa$ B and STAT3 which are the key transcription factors in psoriasis pathogenesis and promote the skin defense system while reducing the expression of immune mediators and epidermal proliferation (Lee et al., 2020). Further proving our subject, 2,3,7,8tetrachlorodibenzo-p-dioxin (TCDD) aggravated IMQ-induced psoriasis by increasing the expression of phosphorylated NF- $\kappa \mathrm{B}$ p65 and inhibiting the antioxidant marker Nrf2 (Kim et al., 2021). These studies have provided a novel and clinically meaningful perspective on the pathogenesis and therapeutic targets of psoriasis in the world.

Experimental results from other perspectives have also demonstrated the importance of the Nrf2 and NF- $\kappa B$ pathways in skin inflammation, especially psoriasis. Fumarate esters (FAEs) such as dimethyl fumarate (DMF) and its active metabolite monomethyl fumarate (MMF) can play a vital role in the treatment of psoriasis because of their immunomodulatory effects (Brück et al., 2018). On the one hand, the binding of DMF and MMF to the cysteine residues of Keap1 induces a conformational change that dissociates Nrf2 from Keap1 and enters the nucleus, thereby activating cytoprotective and antiinflammatory genes (Linker et al., 2011). On the other hand, DMF can also directly or indirectly inhibit the nuclear activity of $\mathrm{NF}-\kappa \mathrm{B}$, affecting cytokine production in human $\mathrm{T}$ cells, human breast cancer cell lines, and mouse dendritic cells (Gerdes et al., 2007; Ghoreschi et al., 2011; Kastrati et al., 2016).

Interestingly, some researchers have found that synchronized circadian clocks could not only enhance the protective role of Nrf2 but also attenuate the validated response through the NF- $\kappa B$ signaling pathway when testing the differential responses of keratinocytes clock synchronized or desynchronized in challenged keratinocytes by $\mathrm{O} 3$. The synchronized circadian clocks can strengthen the cellular defense function and alleviate skin inflammation, which provides new insight into the crosstalk of Nrf2 and NF-kB (Frigato et al., 2020).

\section{NEUROTOXICITY}

Chemotherapy agents such as oxaliplatin, cisplatin, paclitaxel, and bortezomib frequently cause severe peripheral neuropathy and there is currently no effective strategy to prevent druginduced toxicity.

\subsection{Cisplatin-Induced Neurotoxicity}

Cisplatin can cause not only nephrotoxicity but also cause severe neurotoxicity, which significantly limits its clinical use. A study showed that a continuous high dose of cisplatin stimulation disrupted the blood-brain barrier, leading to brain cell edema and neuronal necrosis (Namikawa et al., 2000). Regarding the study of prevention and treatment of cisplatin-induced neurotoxicity, the neuroprotective effects exerted by many agents are closely related to the $\mathrm{Nrf} 2$ and NF- $\mathrm{BB}$ pathways. Schisandrin B (Sch B) has been reported earlier to effectively inhibit the activation of NF- $\kappa \mathrm{B}, \mathrm{p} 53$ and cleave caspase- 3 expression in cisplatin-treated mice, thereby exerting the efficacy of protective drugs (Giridharan et al., 2012). Recently, a large number of articles have found that agents including edaravone and epigallocatechin-3-gallate (EGCG) prevented the development of cisplatin-related brain inflammation and oxidative damage by up-regulating the gene expression level of the Nrf2/HO-1 pathway and preventing the cisplatin-induced NF- $\kappa$ B activation (Jangra et al., 2016; Arafa and Atteia, 2020).

\subsection{Bortezomib-Induced Neurotoxicity}

Bortezomib was the first proteasome inhibitor approved to treat multiple myeloma (MM), mantle cell lymphoma, and other solid tumors. However, peripheral neuropathy (PNP) is one of the most common side effects of bortezomib and leads to dose modification and discontinuation of therapy. One hallmark of 
the mechanism of action of bortezomib in tumor cells is NF-kB, while bortezomib treatment may induce neuropathy by inhibiting $\mathrm{NF}-\kappa \mathrm{B}$ in non-neuronal types or targeting other signaling pathways. It has been found that animals with impaired NF$\kappa \mathrm{B}$ activation developed significantly less neuropathy, suggesting that the NF- $\mathrm{BB}$ activation played an active role in bortezomibinduced neuropathy (Alé et al., 2016). There was also evidence to identify the NF- $\kappa B$ signaling pathway mediating neurotoxicity when investigating the molecular factors associated with PNP in patients with MM induced by bortezomib (Campo et al., 2017). Thus, inhibition of NF- $\kappa$ B may be a promising strategy to protect against bortezomib-triggered neurotoxicity.

\subsection{Paclitaxel (PTX) and Qxalipatin-Induced Neurotoxicity}

PTX is an anti-tumor drug with high efficacy, especially for breast cancer, ovarian cancer, bladder cancer, lung cancer, and other types of solid tumors (Melli et al., 2006; Malekinejad et al., 2016). Despite its dramatic effect, PTX can cause severe peripheral neuropathy (usually manifested as painful neuropathy), affecting up to $50 \%$ of cancer patients (Hu L. Y et al., 2019). Huangqi Guizhi Wuwu Decoction (HGWD) was found to have a therapeutic effect on oxaliplatin-induced peripheral neuropathy. It was revealed that HGWD significantly inhibited PTX -induced activation of TLR4/NF- $\kappa \mathrm{B}$ and decreased the expression of I $\kappa \mathrm{Ka}$, and phosphorylation of NF- $\kappa \mathrm{B}$ to inhibit PTX-evoked inflammatory and oxidative responses in the peripheral nervous system. It also promoted activation of the PI3K/AktNrf2 signaling pathway, alleviating PTX-induced oxidative stress to some extent ( $\mathrm{Lv}$ et al., 2021). Moreover, other protective drugs have also been shown to regulate the downstream Nrf2/HO-1 pathway (Yardim et al., 2021). Another chemotherapeutic drug, oxaliplatin, also often causes peripheral neuropathy afflicting patients. However, some studies have found that L-carnosine exerted a neuroprotective effect against oxaliplatin-induced peripheral neuropathy in colorectal cancer patients via the Nrf2 and NF- $\kappa B$ pathways (Yehia et al., 2019).

According to the results of another study, we reasonably hypothesize that the protective mechanism against chemotherapy-induced neurotoxicity may be that protective drugs and their metabolites increase the DNA-binding activity of $\mathrm{Nrf2}$, thereby enhancing the ability to counteract oxidative stress (Kawashiri et al., 2018). On the other hand, the potential inhibitory effect of Nrf2 on NF- $\kappa \mathrm{B}$ inhibits the inflammatory response and enhances the alleviation of neurotoxicity. However, it is noteworthy that elevation of Nrf2 signaling by protective agents can also activate the phase I, II and III response in tumors. Increased expression of xenobiotic metabolism and efflux pumps due to compounds (protective agents mentioned above) that elevate Nrf2 in cancer maybe diminish anti-cancer agent efficacy. These concerns may be diminished due to co-administration agents possessing, such as pharmacokinetic properties which cause differential temporal effects, and treatment regimens that cause increased metabolism/ efflux transporter expression only after anti-cancer agents have already bound to their target. Other effects such as organ-specific compound uptake and other variables could also be explained.
Notably, differences between genetic and pharmacologic activation of Nrf2 signaling also exist (Kensler and Wakabayashi, 2010).

\subsection{The Crosstalk Between Nrf2 and NF-kB in Neurodegenerative Disorders}

Suppression of Nrf2 can cause the development of neurotoxicity in animal models (Sandberg et al., 2014). Previous studies have reported that $\mathrm{Nrf} 2$ deficient mice developed vacuolar (spongiform) leukoencephalopathy along with extensive astrogliosis, revealing a possible physiological role for Nrf2 in maintaining myelin in the central nervous system (Hubbs et al., 2007). A dysfunctional Nrf2 system may increase the risk of chronic diseases in humans, such as Alzheimer's disease (AD) and Parkinson's disease (PD). A study in neurodegenerative disease showed that the amount of Nrf2 was decreased in hippocampal astrocytes which were one of the brain regions where neurodegeneration began in $\mathrm{AD}$ patients. Also, in $\mathrm{PD}$ patients, the nuclear localization of Nrf2 is strongly induced, but this response may not be sufficient to protect neurons from degeneration (Ramsey et al., 2007). In addition, genetic variants in the Nrf2 gene have been associated with the progression of $\mathrm{AD}$ and $\mathrm{PD}$ (von Otter et al., 2010a; von Otter et al., 2010b). Several studies have shown that NF- $\kappa B$ activation in astrocytes could aggravate neuroinflammation and produce neurotoxic effects (Schwaninger et al., 1999; Acarin et al., 2001; de Freitas et al., 2002; Brambilla et al., 2005). In addition, the expression of various NF- $\kappa \mathrm{B}$ target genes and NF- $\kappa B$ DNA-binding activity increased in the brains of $\mathrm{AD}$ patients (Hensley, 2010). Several genetic, cell biology, biochemical and animal studies supported that inhibiting NF$\kappa \mathrm{B}$ could play a critical role in preventing the development of $\mathrm{AD}$ pathology (Selkoe, 2001; Ghiso and Frangione, 2002).

Consistent with the above content, a study showed that DMF is involved in protecting $\beta$-amyloid-induced cytotoxicity and alleviating neurotoxicity by reducing the pro-inflammatory pathway: NF- $\kappa B$, as well as regulating the Nrf2 pathway to increase the production of antioxidant enzymes (Campolo et al., 2018). A study found that DMF exerted neuroprotective effects through the crosstalk between Nrf2 and NF- $\kappa B$ pathways in vitro and in vivo, besides regulating antioxidant enzymes such as Nrf2, Mn-SOD, and HO-1, thereby reducing the levels of proinflammatory cytokines such as IL-1 and iNOS (Campolo et al., 2017). The study also has elucidated the crosstalk between Nrf2 and NF- $\mathrm{BB}$ pathways in acrylamide-induced neurotoxicity and found that the protective effect of oxidant N-Acetyl-L-Cysteine (NAC) against acrylamide was to resist cell injury by activating the Nrf2 pathway and inhibiting NF- $\mathrm{B}$ pathway. In addition, MAPKs, as the central mediators that transmit extracellular signals from cell membrane to nucleus, can regulate the activation of Nrf2 and NF- $\kappa B$ pathways to reduce cell injuries (Pan et al., 2018). Vincristine was proved to increase NF- $\kappa B$ levels in sciatic nerves and consequently cause oxidative stress and neuroinflammation through the suppression of the Nrf2 pathway. Meanwhile, the quercetin treatment increased Nrf2 levels and downregulated NF- $\mathrm{BB}$ levels to alleviate oxidative stress and neuroinflammation (Yardim et al., 2020). Another research 
TABLE 1 | A summary of representative protective agents targeting the crosstalk between the Nrf2 and NF-kB pathway in drug-induced toxicity.

$\begin{array}{cccc}\text { Toxic reaction } & \begin{array}{c}\text { Representative } \\ \text { drug }\end{array} & \begin{array}{c}\text { Representative } \\ \text { promising candidate }\end{array} & \begin{array}{c}\text { Brief summary of } \\ \text { regulatory mechanisms based } \\ \text { on Nrf2 and NF- } \mathrm{kB}\end{array}\end{array}$

Hepatotoxicity Acetaminophen Salvianolic acid B/C

Farrerol; Tanshinone IIA

Maltol; Wuzhi tablet

Rutaecarpine; Quercetin

Tovophyllin A

Limonin; Daphnetin Licochalcone A

Isoniazid

Gallic acid; Quercetin

Pyrrolidine

dithiocarbamate

Sagittaria sagittifolia

Triptolide

Polygonum

multiflorum

Nephrotoxicity Cisplatin

Arctiin; Quercetin; Licorice

Panax notoginseng

saponins

Sulforaphane; Catalpol

Pioglitazone

Cordyceps cicadae Mycelia

Vincamine; Embelin; Polysulfide Celastrol; Gliclazide;

Vanillin

Thymoquinone and

Curcumin

Bardoxolone methyl

Sedum sarmentosum extract

Atorvastatin; Infliximab; stanniocalcin-1

Lansoprazole;

Sulforaphane
- Regulating drug-metabolizing enzymes, transporter and antioxidant genes through the Nrf2/ARE pathway

- Mitigating mitochondrial oxidative stress, inflammatory response, and caspasemediated antiapoptotic effect through inhibition of Keap1/Nrf2/HO-1 axis

- Exerting antioxidant effects through Nrf2 activation via the AMPK/AKT pathway

- Upregulating AMPK/GSK3ß-Nrf2 signaling pathway

- Inhibiting oxidative stress and inflammation response via NF-kB and PI3K/Akt pathway

- Activating the Nrf2 pathway and inhibiting NF$\kappa \mathrm{B}$ inflammatory response via upregulating Sirt1

- Regulating Nrf2/Trx-1 axis via decreasing ASK1/JNK and Txnip/NLRP3 inflammasome

- Increasing the expression of antioxidant enzymes and decreasing CYP expression through the activation of the Nrf2/Keap1 pathway

- Increasing BSEP expression, and exhibiting + antioxidant and anti-inflammatory activities

- Improving the redox homeostasis by activating Nrf2 and blocking NF-kB/TLR-4 axis

- Acting as an upstream activator to regulate Nrf2 and its downstream target (HO1, NQO1)

- Inducing phase $\mathrm{I} / \mathrm{II}$ detoxification enzyme via Nrf2 pathway to increasing metabolic conversion

- Restoring Th17/Treg balance through Tim-3 and TLR4-MyD88-NF-кB pathway

- Decreasing serum TNF- $a$ and other inflammatory cytokines, liver tissue PPAR- $\gamma$ expression, and inhibiting expression of NFкB p65

- Decreasing phosphorylation of STAT3 and I $K K \beta$

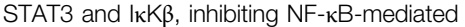
inflammatory cascade and improving mitochondrial function

- Diminishing oxidative stress and inflammation by activating the signaling pathway of $\mathrm{Nrf2} / \mathrm{HO}$ 1 and impeding NF-kB

- Upregulating Nrf2/Smad7, NQO1, and HO-1 expression and downregulating Keap1 expression

- Decreasing the activity of the NF-кB signaling pathway, resulting in down-regulated expression of NF-kB-controlled chemokines and pro-inflammatory cytokines

- Activating the Nrf2/Sirt3/SOD2 or Nrf2/HO-1 pathways

- Suppressing the TLR4/Myd88 pathway and inhibiting the expression of downstream inflammatory cytokines, such as $\mathrm{IL}-1 \beta, \mathrm{TNF}-\alpha$, $\mathrm{IL}-6$, and MCP-1
Wang et al. (2019a), Lv et al. (2019), Wu et al. (2019), Wang et al. (2019b), Ibrahim et al. (2018), Rada et al. (2018), Yang et al. (2020), Choi et al. (2021), Fan et al. (2014), Jiet al. (2015), Fan et al. (2018), Lv et al. (2018), Lv et al. (2020), Zhang et al. (2020)

Wang et al. (2018), Jia et al. (2019), Zhang et al (2019), He et al. (2020), Sanjay et al. (2021a), Sanjay et al. (2021b)

Zhou et al. (2020), Feng et al. (2019), Fu et al. (2020), Wei et al. (2017), Yuan et al. (2020), Li et al. (2014b), Hou et al. (2018)

Meng et al. (2017)

Yu et al. (2018), Deng et al. (2020), Qin et al. (2019), Al Fayi et al. (2020), Sun et al. (2020), Taghizadeh et al. (2020), Younis et al. (2020), El-Sayed et al. (2021)

Wu et al. (2014), Song et al. (2019), Bai et al. (2014)

Saritemur et al. (2015), Khaleel et al. (2017), Yue et al. (2017), Khaleel et al. (2019), Zhou Z et al. (2019), Zhao et al. (2020)

(Continued on following page) 
TABLE 1 | (Continued) A summary of representative protective agents targeting the crosstalk between the Nrf2 and NF-kB pathway in drug-induced toxicity.

\begin{tabular}{|c|c|c|c|c|}
\hline Toxic reaction & $\begin{array}{l}\text { Representative } \\
\text { drug }\end{array}$ & $\begin{array}{l}\text { Representative } \\
\text { promising candidate }\end{array}$ & $\begin{array}{l}\text { Brief summary of } \\
\text { regulatory mechanisms based } \\
\text { on Nrf2 and NF-кB }\end{array}$ & References \\
\hline & & Tert-Butylhydroquinone & $\begin{array}{l}\text { - Alleviating oxidative DNA damage, } \\
\text { mitochondrial damage and apoptosis via the } \\
\text { Nrf2 pathway }\end{array}$ & \\
\hline & Gentamicin & $\begin{array}{l}\text { Diallyl sulfide; Diosmin } \\
\text { Melatonin; Kiwi fruit }\end{array}$ & 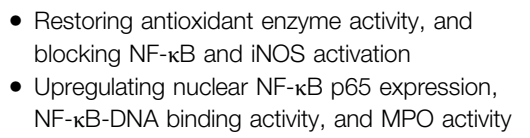 & $\begin{array}{l}\text { Tugcu et al. (2006), Kalayarasan et al. (2009), Lee } \\
\text { et al. (2012), Ansari et al. (2016), Arjinajarn et al. } \\
\text { (2016), Mahmoud (2017), Ali et al. (2021) }\end{array}$ \\
\hline & & $\begin{array}{l}\text { Pyrolidium } \\
\text { dithiocarbamate } \\
\text { sulfasalazine; Sinapic acid } \\
\text { Riceberry bran extract }\end{array}$ & $\begin{array}{l}\text { - Activating Keap1/Nrf2/ARE, AKT or PKC/Nrf2 } \\
\text { antioxidant pathways }\end{array}$ & \\
\hline & Methotrexate & $\begin{array}{l}\text { Berberine; Chicoric acid; } \\
\text { Dioscin }\end{array}$ & $\begin{array}{l}\text { - Activating Keap1/Nrf2 signaling and } \\
\text { attenuating ROS-induced activation of NF-кB/ } \\
\text { NLRP3 inflammasome signaling and apoptosis } \\
\text { pathways }\end{array}$ & $\begin{array}{l}\text { Hassanein et al. (2018), Mahmoud et al. (2018), } \\
\text { Abd El-Twab et al. (2019), Aladaileh et al. (2019), } \\
\text { Hassanein et al. (2019), Shalaby et al. (2019), } \\
\text { Sherif et al. (2020), Li et al. (2021c) }\end{array}$ \\
\hline & & $\begin{array}{l}\text { Commiphora molmol; } \\
\text { Vincamine } \\
\text { Formononetin; } \\
\text { Umbelliferone }\end{array}$ & $\begin{array}{l}\text { - Regulating antioxidant pathways and anti- } \\
\text { inflammatory pathways via miR145-5p or } \\
\text { miR29a }\end{array}$ & \\
\hline Cardiotoxicity & Doxorubicin & $\begin{array}{l}\text { Asiatic acid; Apigenin; } \\
\text { Geraniol } \\
\text { Cardamonin; Baicalein; } \\
\text { Dioscin } \\
\text { sulforaphane; } \\
\text { tanshinone IIA } \\
\text { Trifluoperazine; Wheat } \\
\text { phenolics }\end{array}$ & $\begin{array}{l}\text { - Activating the Nrf2/Keap1/ARE pathway } \\
\text { - Inhibiting oxidative stress, MAP kinase } \\
\text { activation, NF-kB pathway, PI3K/Akt/mTOR } \\
\text { impairment, and cardiac apoptosis }\end{array}$ & $\begin{array}{l}\text { Qi et al. (2020), Yarmohammadi et al. (2021), } \\
\text { Sahu et al. (2019), Goda et al. (2021), Younis } \\
\text { et al. (2021) }\end{array}$ \\
\hline $\begin{array}{l}\text { Pulmonary } \\
\text { Toxicity }\end{array}$ & Bleomycin & $\begin{array}{l}\text { Artemisitene; Curcumin } \\
\text { Hesperidin; Pirfenidone } \\
\text { Glycyl-L-histidyl-I-lysine } \\
\text { Salidroside; } \\
\text { Thymoquinone } \\
\text { Walnut extract }\end{array}$ & 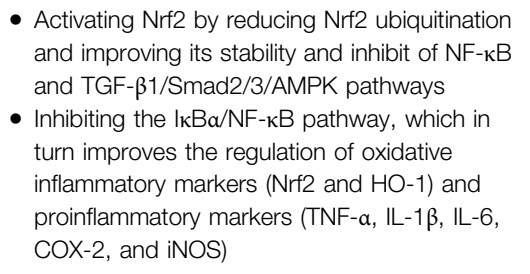 & $\begin{array}{l}\text { Chen et al. (2016), Tang et al. (2016), Beigh et al. } \\
\text { (2017), Liu et al. (2017b), Zhou Z et al. (2019), } \\
\text { Ahmad et al. (2020), Ma et al. (2020), Shaikh and } \\
\text { Prabhakar Bhandary (2020) }\end{array}$ \\
\hline \multirow[t]{2}{*}{ Dermal toxicity } & Imiquimod & Dimethylfumarate & $\begin{array}{l}\text { - Attenuating psoriasis-related inflammatory, } \\
\text { regulating cellular anti-oxidant responses and } \\
\text { suppression of keratinocyte hyperproliferation } \\
\text { via activation of Nrf2/HO1 and inhibition of NF- } \\
\text { кB and STAT3 }\end{array}$ & $\begin{array}{l}\text { Lee et al. (2020), Sangaraju et al. (2021), Ogawa } \\
\text { et al. (2020) }\end{array}$ \\
\hline & & $\begin{array}{l}\text { Tussilagonone (TGN) } \\
\text { Galangin }\end{array}$ & $\begin{array}{l}\text { - Influencing cytokine production by antigen- } \\
\text { presenting cells, inhibiting Th1/Th12 } \\
\text { responses, promoting Th2 responses via } \\
\text { indirect and/or direct inhibition of NF-kB }\end{array}$ & \\
\hline \multirow[t]{6}{*}{ Neurotoxicity } & Cisplatin & $\begin{array}{l}\text { Epigallocatechin Gallate } \\
\text { Edaravone; Schisandrin B }\end{array}$ & $\begin{array}{l}\text { - Inhibiting NF-кB and p53 activation and } \\
\text { upregulating Nrf2/HO-1 pathway }\end{array}$ & $\begin{array}{l}\text { Giridharan et al. (2012), Jangra et al. (2016), } \\
\text { Arafa and Atteia (2020) }\end{array}$ \\
\hline & Bortezomib & Dimethyl fumarate & - Activating the Nrf2 pathway & Kawashiri et al. (2018) \\
\hline & $\begin{array}{l}\text { Paclitaxel and } \\
\text { Qxalipatin }\end{array}$ & $\begin{array}{l}\text { Curcumin; Dimethyl } \\
\text { fumarate }\end{array}$ & $\begin{array}{l}\text { - Inhibiting activation of the inflammatory TLR4/ } \\
\text { NF-kB pathway and promoting the activation of } \\
\text { PI3K/Akt-Nrf2 signaling pathway }\end{array}$ & $\begin{array}{l}\text { Kawashiri et al. (2018), Yehia et al. (2019), Lv } \\
\text { et al. (2021), Yardım et al. (2021) }\end{array}$ \\
\hline & & Huangqi Guizhi Wuwu & - Protecting neural stem/progenitor cells and & \\
\hline & & Decoction (HGWD) & neurons from oxidative damage through the & \\
\hline & & L-Carnosine & Nrf2-ERK1/2 MAPK pathway & \\
\hline
\end{tabular}

highlights that acrylamide, a common food contaminant formed during food heat processing, induces oxidative stress in astrocytes and microglia by regulating the Nrf2/ARE and NF- $\kappa B$ pathways, leading to neurotoxicity. These results reveal the importance of the crosstalk of Nrf2 and NF- $\kappa \mathrm{B}$ signal pathways in neurotoxicity (Zhao et al., 2017).

Furthermore, it has been proved that mice bearing Nrf2 deficiency were suffered from neuroinflammation and lost 


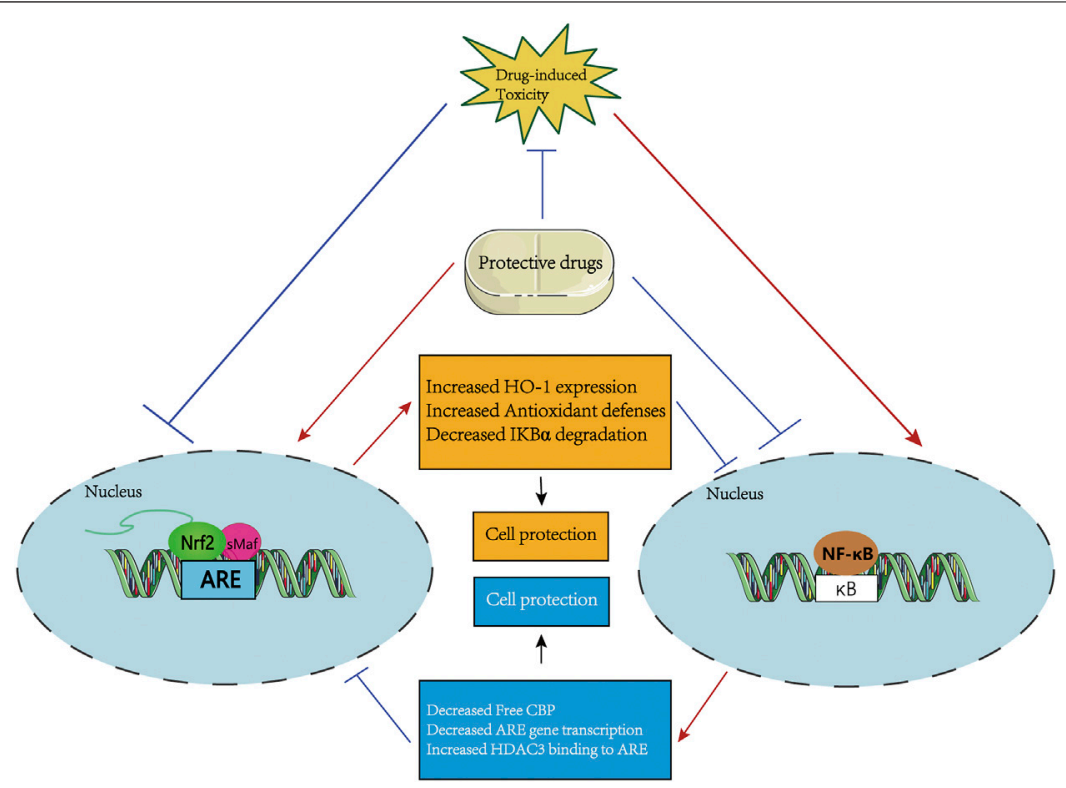

FIGURE 4 | A systematic schematic of protective agents against drug-induced toxicity via modulating the mutual interference between Nrf2 and NF- $\kappa B$ pathways. The protective candidates improve the antioxidant capacity by activating the Nrf2 pathway and inhibiting the NF-кB-mediated inflammatory response, thereby antagonizing the drug-induced organ toxicity. Specifically, on the one hand, the protective agents directly or indirectly activate the Nrf2 signaling, then prevent IkBa degradation, or increase $\mathrm{HO}-1$ expression to inhibit NF-kB activation, thereby increasing antioxidant defense ability to resist drug-induced toxicity. On the other hand, the protective agents may inhibit the nuclear translocation of NF-kB which activating by drug-induced toxicity to increase the activation of the Nrf2 pathway by increasing ARE gene transcription and Free CBP, and reducing the recruitment of HDAC3 to the ARE region.

dopaminergic neurons (Lastres-Becker et al., 2012). By comparison, the neuroprotection appeared in a mutant alphasynuclein (aSyn; a small protein with 140 amino acids abundant in presynaptic nerve terminals) transgenic mouse model with an overexpression level of Nrf2 gene (Gan et al., 2012). At the same time, the increased activation of NF- $\mathrm{KB}$ is related to the strong nuclear $\mathrm{p} 65$ immunoreactivity in $\mathrm{PD}$ patients, which suggests that NF- $\kappa \mathrm{B}$ participates in neurodegenerative disorder (Mattson and Camandola, 2001). Also, evidence has shown that we could take $\mathrm{NF}-\kappa \mathrm{B}$ as an ideal therapeutic target due to its critical role in forming inflammatory mediators in models of PD-induced neurotoxicity (Flood et al., 2011). Thus, it is obvious that Nrf2 and NF- $\kappa \mathrm{B}$ interplay in neurodegenerative disorders, in which the increase of NF- $\kappa B$ aggravates neuroinflammation while the increase of Nrf2 affords neuroprotection (Sivandzade et al., 2019).

\section{THERAPEUTICAL STRATEGIES FOR DRUG-INDUCED ADVERSE REACTIONS}

Here, we summarize the protective agents that may alleviate injury in different organ toxicities as well as their effects in antioxidative and anti-inflammatory systems (Table $\mathbf{1}$ ).

\section{PERSPECTIVES AND CONCLUSION}

In clinical applications, the treatment of many drugs, including APAP and antineoplastic agents, is limited by their potential organ toxicity. However, the mechanism of drug-induced tissue injury and the corresponding protective strategies have not been fully discussed. Meanwhile, there is increasing interest in investigating the relevance of $\mathrm{Nrf} 2$ and $\mathrm{NF}-\kappa \mathrm{B}$ signaling pathways in the development/progression of drug-induced injury. Therefore, this review summarizes and discusses the role of common agents in the induction of multiple organ toxicities. We found that the unbalanced relationship between Nrf2 and NF- $\mathrm{kB}$ may induce or aggravate toxic responses, while substances that regulate the relationship between Nrf2 and NF- $\kappa \mathrm{B}$ may play a protective rolerestoring Nrf2 activity, thereby enhancing antioxidant capacity and reducing NF- $\kappa \mathrm{B}$-mediated inflammatory responses. The crosstalk of both may serve as a central hub for drug-induced toxic responses. At the same time, drugs or therapeutic approaches that target the crosstalk between Nrf2 and NF- $\kappa B$ appear to be promising pointcuts for future clinical responses to drug-induced toxicity (Figure 4). In addition, further study and therapeutic exploration of potential molecular mechanisms will help explain the specific regulatory mechanisms of Nrf2 and NF- $\kappa B$ signaling pathways in various drug-induced organ toxicities, and ultimately standardize rational and safe medicine usage and reduce the occurrence of toxic reactions. In summary, we urgently need signaling network studies of Nrf2 and NF- $\kappa \mathrm{B}$ in pathological situations, as well as new treatments and new drugs targeting the crosstalk between the two.

\section{AUTHOR CONTRIBUTIONS}

WG, LG, and MY contributed to the conception and design of the review. WG and LG drafted the work and revised it critically for 
the whole manuscript. YY and YW are responsible for the manuscript structure and English grammar. SX and HG gave feedback and suggestions for the article. B-KZ and MY gave final approval of the review to be published. All authors contributed to manuscript revision, read, and approved the submitted version.

\section{REFERENCES}

Abd El-Twab, S. M., Hussein, O. E., Hozayen, W. G., Bin-Jumah, M., and Mahmoud, A. M. (2019). Chicoric Acid Prevents Methotrexate-Induced Kidney Injury by Suppressing NF-Kb/nlrp3 Inflammasome Activation and Up-Regulating Nrf2/ARE/HO-1 Signaling. Inflamm. Res. 68 (6), 511-523. doi:10.1007/s00011-019-01241-z

Acarin, L., Gonza'lez, B., and Castellano, B. (2001). Triflusal Posttreatment Inhibits Glial Nuclear Factor-Kb, Downregulates the Glial Response, and Is Neuroprotective in an Excitotoxic Injury Model in Postnatal Brain. Stroke 32 (10), 2394-2402. doi:10.1161/hs1001.097243

Ahmad, A., Alkharfy, K. M., Jan, B. L., Ahad, A., Ansari, M. A., Al-Jenoobi, F. I., et al. (2020). Thymoquinone Treatment Modulates the Nrf2/HO-1 Signaling Pathway and Abrogates the Inflammatory Response in an Animal Model of Lung Fibrosis. Exp. Lung Res. 46 (3-4), 53-63. doi:10.1080/ 01902148.2020.1726529

Ahmed, S. M. U., Luo, L., Namani, A., Wang, X. J., and Tang, X. (2017). Nrf2 Signaling Pathway: Pivotal Roles in Inflammation. Biochim. Biophys. Acta (Bba) - Mol. Basis Dis. 1863 (2), 585-597. doi:10.1016/j.bbadis.2016.11.005

Al Fayi, M., Otifi, H., Alshyarba, M., Dera, A. A., and Rajagopalan, P. (2020). Thymoquinone and Curcumin Combination Protects Cisplatin-Induced Kidney Injury, Nephrotoxicity by Attenuating NFkB, KIM-1 and Ameliorating Nrf2/HO-1 Signalling. J. Drug Target. 28 (9), 913-922. doi:10.1080/1061186X.2020.1722136

Aladaileh, S. H., Hussein, O. E., Abukhalil, M. H., Saghir, S. A. M., Bin-Jumah, M., Alfwuaires, M. A., et al. (2019). Formononetin Upregulates Nrf2/HO-1 Signaling and Prevents Oxidative Stress, Inflammation, and Kidney Injury in Methotrexate-Induced Rats. Antioxidants 8 (10), 430. doi:10.3390/ antiox 8100430

Alé, A., Bruna, J., Calls, A., Karamita, M., Haralambous, S., Probert, L., et al. (2016). Inhibition of the Neuronal NFkB Pathway Attenuates Bortezomib-Induced Neuropathy in a Mouse Model. Neurotoxicology 55, 58-64. doi:10.1016/ j.neuro.2016.05.004

Ali, F. E. M., Sayed, A. M., El-Bahrawy, A. H., Omar, Z. M. M., and Hassanein, E. H. M. (2021). Targeting KEAP1/Nrf2, AKT, and PPAR- $\gamma$ Signals as a Potential Protective Mechanism of Diosmin against Gentamicin-Induced Nephrotoxicity. Life Sci. 275, 119349. doi:10.1016/j.lfs.2021.119349

Andrade, R. J., Aithal, G. P., Björnsson, E. S., Kaplowitz, N., Kullak-Ublick, G. A., Larrey, D., et al. (2019). EASL Clinical Practice Guidelines: Drug-Induced Liver Injury. J. Hepatol. 70 (6), 1222-1261. doi:10.1016/j.jhep.2019.02.014

Ansari, M. A., Raish, M., Ahmad, A., Ahmad, S. F., Mudassar, S., Mohsin, K., et al. (2016). Sinapic Acid Mitigates Gentamicin-Induced Nephrotoxicity and Associated Oxidative/nitrosative Stress, Apoptosis, and Inflammation in Rats. Life Sci. 165, 1-8. doi:10.1016/j.lfs.2016.09.014

Arafa, M. H., and Atteia, H. H. (2020). Protective Role of Epigallocatechin Gallate in a Rat Model of Cisplatin-Induced Cerebral Inflammation and Oxidative Damage: Impact of Modulating NF-Kb and Nrf2. Neurotox Res. 37 (2), 380-396. doi:10.1007/s12640-019-00095-x

Arjinajarn, P., Pongchaidecha, A., Chueakula, N., Jaikumkao, K., Chatsudthipong, V., Mahatheeranont, S., et al. (2016). Riceberry Bran Extract Prevents Renal Dysfunction and Impaired Renal Organic Anion Transporter 3 (Oat3) Function by Modulating the PKC/Nrf2 Pathway in Gentamicin-Induced Nephrotoxicity in Rats. Phytomedicine 23 (14), 1753-1763. doi:10.1016/ j.phymed.2016.10.014

Bai, Y., Lu, H., Hu, L., Hong, D., Ding, L., and Chen, B. (2014). Effect of Sedum Sarmentosum BUNGE Extract on Aristolochic Acid-Induced Renal Tubular Epithelial Cell Injury. J. Pharmacol. Sci. 124 (4), 445-456. doi:10.1254/ jphs.13216fp

\section{FUNDING}

This work was supported by the National Natural Science Foundation of China (Grant No. 81974532) and the Natural Science Foundation of Hunan Province, China (Grant No. 2020JJ4130).

Beigh, S., Rashid, H., Sharma, S., Parvez, S., and Raisuddin, S. (2017). Bleomycininduced Pulmonary Toxicopathological Changes in Rats and its Prevention by walnut Extract. Biomed. Pharmacother. 94, 418-429. doi:10.1016/ j.biopha.2017.07.124

Bellezza, I., Mierla, A. L., and Minelli, A. (2010). Nrf2 and NF-Kb and Their Concerted Modulation in Cancer Pathogenesis and Progression. Cancers 2 (2), 483-497. doi:10.3390/cancers2020483

Bellezza, I., Tucci, A., Galli, F., Grottelli, S., Mierla, A. L., Pilolli, F., et al. (2012). Inhibition of NF-Kb Nuclear Translocation via HO-1 Activation Underlies atocopheryl Succinate Toxicity. J. Nutr. Biochem. 23 (12), 1583-1591. doi:10.1016/j.jnutbio.2011.10.012

Boehncke, W.-H., and Schön, M. P. (2015). Psoriasis. The Lancet 386 (9997), 983-994. doi:10.1016/s0140-6736(14)61909-7

Brambilla, R., Bracchi-Ricard, V., Hu, W.-H., Frydel, B., Bramwell, A., Karmally, S., et al. (2005). Inhibition of Astroglial Nuclear Factor $\kappa B$ Reduces Inflammation and Improves Functional Recovery after Spinal Cord Injury. J. Exp. Med. 202 (1), 145-156. doi:10.1084/jem.20041918

Brown, S.-A., Sandhu, N., and Herrmann, J. (2015). Systems Biology Approaches to Adverse Drug Effects: the Example of Cardio-Oncology. Nat. Rev. Clin. Oncol. 12 (12), 718-731. doi:10.1038/nrclinonc.2015.168

Brück, J., Dringen, R., Amasuno, A., Pau-Charles, I., and Ghoreschi, K. (2018). A Review of the Mechanisms of Action of Dimethylfumarate in the Treatment of Psoriasis. Exp. Dermatol. 27 (6), 611-624. doi:10.1111/exd.13548

Buckley, N. A., Buckley, N., Whyte, I. M., O’Connell, D. L., and Dawson, A. H. (1999). Oral or IntravenousN-Acetylcysteine: Which Is the Treatment of Choice for Acetaminophen (Paracetamol) Poisoning? J. Toxicol. Clin. Toxicol. 37 (6), 759-767. doi:10.1081/clt-100102453

Buendia, I., Michalska, P., Navarro, E., Gameiro, I., Egea, J., and León, R. (2016). Nrf2-ARE Pathway: An Emerging Target against Oxidative Stress and Neuroinflammation in Neurodegenerative Diseases. Pharmacol. Ther. 157, 84-104. doi:10.1016/j.pharmthera.2015.11.003

Campo, C., Da Silva Filho, M. I., Weinhold, N., Goldschmidt, H., Hemminki, K., Merz, M., et al. (2017). Genetic Susceptibility to Bortezomib-Induced Peripheral Neuroropathy: Replication of the Reported Candidate Susceptibility Loci. Neurochem. Res. 42 (3), 925-931. doi:10.1007/s11064016-2007-9

Campolo, M., Casili, G., Biundo, F., Crupi, R., Cordaro, M., Cuzzocrea, S., et al. (2017). The Neuroprotective Effect of Dimethyl Fumarate in an MPTP-Mouse Model of Parkinson's Disease: Involvement of Reactive Oxygen Species/Nuclear Factor- $\kappa \mathrm{B} /$ Nuclear Transcription Factor Related to NF-E2. Antioxid. Redox Signaling 27 (8), 453-471. doi:10.1089/ars.2016.6800

Campolo, M., Casili, G., Lanza, M., Filippone, A., Paterniti, I., Cuzzocrea, S., et al. (2018). Multiple Mechanisms of Dimethyl Fumarate in Amyloid $\beta$-induced Neurotoxicity in Human Neuronal Cells. J. Cel. Mol. Med. 22 (2), 1081-1094. doi: $10.1111 /$ jcmm. 13358

Canning, P., Sorrell, F. J., and Bullock, A. N. (2015). Structural Basis of Keap1 Interactions with Nrf2. Free Radic. Biol. Med. 88 (Pt B), 101-107. doi:10.1016/ j.freeradbiomed.2015.05.034

Chan, K., Han, X.-D., and Kan, Y. W. (2001). An Important Function of Nrf2 in Combating Oxidative Stress: Detoxification of Acetaminophen. Proc. Natl. Acad. Sci. 98 (8), 4611-4616. doi:10.1073/pnas.081082098

Chen, W., Li, S., Li, J., Zhou, W., Wu, S., Xu, S., et al. (2016). Artemisitene Activates the Nrf2-dependent Antioxidant Response and Protects against Bleomycin-induced Lung Injury. FASEB j. 30 (7), 2500-2510. doi:10.1096/ fj.201500109R

Chen, Y.-y., Chiang, S.-y., Wu, H.-c., Kao, S.-t., Hsiang, C.-y., Ho, T.-y., et al. (2010). Microarray Analysis Reveals the Inhibition of Nuclear Factor-Kappa B Signaling by Aristolochic Acid in normal Human Kidney (HK-2) Cells. Acta Pharmacol. Sin 31 (2), 227-236. doi:10.1038/aps.2009.197 
Choi, J. H., Jin, S. W., Lee, G. H., Han, E. H., Hwang, Y. P., and Jeong, H. G. (2021). Rutaecarpine Protects against Acetaminophen-Induced Acute Liver Injury in Mice by Activating Antioxidant Enzymes. Antioxidants 10 (1), 86. doi:10.3390/ antiox10010086

Chowdhry, S., Zhang, Y., McMahon, M., Sutherland, C., Cuadrado, A., and Hayes, J. D. (2013). Nrf2 Is Controlled by Two Distinct $\beta$-TrCP Recognition Motifs in its Neh6 Domain, One of Which Can Be Modulated by GSK-3 Activity. Oncogene 32 (32), 3765-3781. doi:10.1038/onc.2012.388

Chung, W.-B., and Youn, H.-J. (2016). Pathophysiology and Preventive Strategies of Anthracycline-Induced Cardiotoxicity. Korean J. Intern. Med. 31 (4), 625-633. doi:10.3904/kjim.2016.017

Cildir, G., Low, K. C., and Tergaonkar, V. (2016). Noncanonical NF-Kb Signaling in Health and Disease. Trends Mol. Med. 22 (5), 414-429. doi:10.1016/ j.molmed.2016.03.002

Cuadrado, A., Manda, G., Hassan, A., Alcaraz, M. J., Barbas, C., Daiber, A., et al. (2018). Transcription Factor NRF2 as a Therapeutic Target for Chronic Diseases: A Systems Medicine Approach. Pharmacol. Rev. 70 (2), 348-383. doi:10.1124/pr.117.014753

Cuadrado, A., Martín-Moldes, Z., Ye, J., and Lastres-Becker, I. (2014). Transcription Factors NRF2 and NF-Kb Are Coordinated Effectors of the Rho Family, GTP-Binding Protein RAC1 during Inflammation. J. Biol. Chem. 289 (22), 15244-15258. doi:10.1074/jbc.M113.540633

Cuadrado, A. (2015). Structural and Functional Characterization of Nrf2 Degradation by Glycogen Synthase Kinase 3/ $\beta$-TrCP. Free Radic. Biol. Med. 88 (Pt B), 147-157. doi:10.1016/j.freeradbiomed.2015.04.029

Cuzzocrea, S., Mazzon, E., Dugo, L., Serraino, I., Di Paola, R., Britti, D., et al. (2002). A Role for Superoxide in Gentamicin-Mediated Nephropathy in Rats. Eur. J. Pharmacol. 450 (1), 67-76. doi:10.1016/s0014-2999(02) 01749-1

de Almeida, A. J. P. O., de Almeida Rezende, M. S., Dantas, S. H., de Lima Silva, S., de Oliveira, J. C. P. L., de Lourdes Assunção Araújo de Azevedo, F., et al. (2020). Unveiling the Role of Inflammation and Oxidative Stress on Age-Related Cardiovascular Diseases. Oxidative Med. Cell Longevity 2020, 1-20. doi:10.1155/2020/1954398

de Freitas, M. S., Spohr, T. C. L. S., Benedito, A. B., Caetano, M. S., Margulis, B., Lopes, U. G., et al. (2002). Neurite Outgrowth Is Impaired on HSP70-Positive Astrocytes through a Mechanism that Requires NF-Kb Activation. Brain Res. 958 (2), 359-370. doi:10.1016/s0006-8993(02)03682-x

Deng, J.-S., Jiang, W.-P., Chen, C.-C., Lee, L.-Y., Li, P.-Y., Huang, W.-C., et al. (2020). Cordyceps Cicadae Mycelia Ameliorate Cisplatin-Induced Acute Kidney Injury by Suppressing the TLR4/NF-Kb/MAPK and Activating the HO-1/Nrf2 and Sirt-1/AMPK Pathways in Mice. Oxidative Med. Cell Longevity 2020, 1-17. doi:10.1155/2020/7912763

Di Paola, R., Impellizzeri, D., Fusco, R., Cordaro, M., Siracusa, R., Crupi, R., et al. (2016). Ultramicronized Palmitoylethanolamide (PEA-Um ) in the Treatment of Idiopathic Pulmonary Fibrosis. Pharmacol. Res. 111, 405-412. doi:10.1016/ j.phrs.2016.07.010

Dinkova-Kostova, A. T., Kostov, R. V., and Kazantsev, A. G. (2018). The Role of Nrf2 Signaling in Counteracting Neurodegenerative Diseases. FEBS J. 285 (19), 3576-3590. doi:10.1111/febs.14379

Dodson, M., de la Vega, M. R., Cholanians, A. B., Schmidlin, C. J., Chapman, E., and Zhang, D. D. (2019). Modulating NRF2 in Disease: Timing Is Everything. Annu. Rev. Pharmacol. Toxicol. 59, 555-575. doi:10.1146/annurev-pharmtox010818-021856

Dong, H., Slain, D., Cheng, J., Ma, W., and Liang, W. (2014). Eighteen Cases of Liver Injury Following Ingestion of Polygonum Multiflorum. Complement. Therapies Med. 22 (1), 70-74. doi:10.1016/j.ctim.2013.12.008

El-Sayed, R. M., Abo El Gheit, R. E., and Badawi, G. A. (2021). Vincamine Protects against Cisplatin Induced Nephrotoxicity via Activation of $\mathrm{Nrf} 2 / \mathrm{HO}-1$ and Hindering TLR4/IFN-Г/cd44 Cells Inflammatory cascade. Life Sci. 272, 119224. doi:10.1016/j.lfs.2021.119224

Enomoto, A., Itoh, K., Nagayoshi, E., Haruta, J., Kimura, T., Harada, T., et al. (2001). High Sensitivity of Nrf2 Knockout Mice to Acetaminophen Hepatotoxicity Associated with Decreased Expression of ARE-Regulated Drug Metabolizing Enzymes and Antioxidant Genes. Toxicol. Sci. 59 (1), 169-177. doi:10.1093/toxsci/59.1.169

Eschenhagen, T., Force, T., Ewer, M. S., de Keulenaer, G. W., Suter, T. M., Anker, S. D., et al. (2011). Cardiovascular Side Effects of Cancer Therapies: a Position
Statement from the Heart Failure Association of the European Society of Cardiology. Eur. J. Heart Fail. 13 (1), 1-10. doi:10.1093/eurjhf/hfq213

Fan, X., Jiang, Y., Wang, Y., Tan, H., Zeng, H., Wang, Y., et al. (2014). Wuzhi Tablet (Schisandra Sphenanthera Extract) Protects against Acetaminophen-Induced Hepatotoxicity by Inhibition of CYP-Mediated Bioactivation and Regulation of NRF2-ARE and P53/p21 Pathways. Drug Metab. Dispos 42 (12), 1982-1990. doi:10.1124/dmd.114.059535

Fan, X., Lv, H., Wang, L., Deng, X., and Ci, X. (2018). Isoorientin Ameliorates APAP-Induced Hepatotoxicity via Activation Nrf2 Antioxidative Pathway: The Involvement of AMPK/Akt/GSK3 $\beta$. Front. Pharmacol. 9, 1334. doi:10.3389/ fphar.2018.01334

Farag, M. R., Elhady, W. M., Ahmed, S. Y. A., Taha, H. S. A., and Alagawany, M. (2019). Astragalus Polysaccharides Alleviate Tilmicosin-Induced Toxicity in Rats by Inhibiting Oxidative Damage and Modulating the Expressions of HSP70, NF-kB and Nrf2/HO-1 Pathway. Res. Vet. Sci. 124, 137-148. doi:10.1016/j.rvsc.2019.03.010

Feng, Z., Zhou, C., Dong, S., Liu, Z., Liu, T., Zhou, L., et al. (2019). Catalpol and Panax Notoginseng Saponins Synergistically Alleviate Triptolide-Induced Hepatotoxicity through Nrf2/ARE Pathway. Toxicol. Vitro 56, 141-149. doi:10.1016/j.tiv.2019.01.016

Finn, W. F. (2006). The Clinical and Renal Consequences of Contrast-Induced Nephropathy. Nephrol. Dial. Transpl. 21 (6), i2-i10. doi:10.1093/ndt/gfl213

Flood, P. M., Qian, L., Peterson, L. J., Zhang, F., Shi, J.-S., Gao, H.-M., et al. (2011). Transcriptional Factor NF-Kb as a Target for Therapy in Parkinson's Disease. Parkinson's Dis. 2011, 1-8. doi:10.4061/2011/216298

Franceschi, C., Garagnani, P., Morsiani, C., Conte, M., Santoro, A., Grignolio, A., et al. (2018). The Continuum of Aging and Age-Related Diseases: Common Mechanisms but Different Rates. Front. Med. 5, 61. doi:10.3389/ fmed.2018.00061

Frigato, E., Benedusi, M., Guiotto, A., Bertolucci, C., and Valacchi, G. (2020). Circadian Clock and OxInflammation: Functional Crosstalk in Cutaneous Homeostasis. Oxidative Med. Cell Longevity 2020, 1-9. doi:10.1155/2020/ 2309437

Fu, L., Zhou, L., Geng, S., Li, M., Lu, W., Lu, Y., et al. (2020). Catalpol Coordinately Regulates Phase I and II Detoxification Enzymes of Triptolide through CAR and NRF2 Pathways to Reduce Triptolide-Induced Hepatotoxicity. Biomed. Pharmacother. 129, 110379. doi:10.1016/j.biopha.2020.110379

Gan, L., Vargas, M. R., Johnson, D. A., and Johnson, J. A. (2012). Astrocyte-specific Overexpression of Nrf2 Delays Motor Pathology and Synuclein Aggregation throughout the CNS in the Alpha-Synuclein Mutant (A53T) Mouse Model. J. Neurosci. 32 (49), 17775-17787. doi:10.1523/JNEUROSCI.3049-12.2012

Gerdes, S., Shakery, K., and Mrowietz, U. (2007). Dimethylfumarate Inhibits Nuclear Binding of Nuclear Factor ?B but Not of Nuclear Factor of Activated T Cells and CCAAT/enhancer Binding Protein ? in Activated Human T Cells. Br. J. Dermatol. 156 (5), 838-842. doi:10.1111/j.13652133.2007.07779.x

Ghiso, J., and Frangione, B. (2002). Amyloidosis and Alzheimer's Disease. Adv. Drug Deliv. Rev. 54 (12), 1539-1551. doi:10.1016/s0169-409x(02)00149-7

Ghoreschi, K., Brück, J., Kellerer, C., Deng, C., Peng, H., Rothfuss, O., et al. (2011). Fumarates Improve Psoriasis and Multiple Sclerosis by Inducing Type II Dendritic Cells. J. Exp. Med. 208 (11), 2291-2303. doi:10.1084/jem.20100977

Giridharan, V. V., Thandavarayan, R. A., Bhilwade, H. N., Ko, K. M., Watanabe, K., and Konishi, T. (2012). Schisandrin B, Attenuates Cisplatin-Induced Oxidative Stress, Genotoxicity and Neurotoxicity through Modulating NF-Kb Pathway in Mice. Free Radic. Res. 46 (1), 50-60. doi:10.3109/10715762.2011.638291

Goda, A. E., Elenany, A. M., and Elsisi, A. E. (2021). Novel In Vivo Potential of Trifluoperazine to Ameliorate Doxorubicin-Induced Cardiotoxicity Involves Suppression of NF-Kb and Apoptosis. Life Sci. 283, 119849. doi:10.1016/ j.lfs.2021.119849

Gong, D.-J., Wang, L., Yang, Y.-Y., Zhang, J.-J., and Liu, X.-H. (2019). Diabetes Aggravates Renal Ischemia and Reperfusion Injury in Rats by Exacerbating Oxidative Stress, Inflammation, and Apoptosis. Ren. Fail. 41 (1), 750-761. doi:10.1080/0886022X.2019.1643737

Grottelli, S., Ferrari, I., Pietrini, G., Peirce, M., Minelli, A., and Bellezza, I. (2016). The Role of Cyclo(His-Pro) in Neurodegeneration. Ijms 17 (8), 1332. doi:10.3390/ijms17081332

Hassanein, E. H. M., Mohamed, W. R., Shalkami, A.-G. S., Khalaf, M. M., and Hemeida, R. A. M. (2018). Renoprotective Effects of Umbelliferone on 
Methotrexate-Induced Renal Injury through Regulation of Nrf-2/Keap-1, P38MAPK/NF-Kb, and Apoptosis Signaling Pathways. Food Chem. Toxicol. 116 (Pt B), 152-160. doi:10.1016/j.fct.2018.03.041

Hassanein, E. H. M., Shalkami, A.-G. S., Khalaf, M. M., Mohamed, W. R., and Hemeida, R. A. M. (2019). The Impact of Keap1/Nrf2, P38MAPK/NF-Kb and $\mathrm{Bax} / \mathrm{Bcl} 2 /$ caspase-3 Signaling Pathways in the Protective Effects of Berberine against Methotrexate-Induced Nephrotoxicity. Biomed. Pharmacother. 109, 47-56. doi:10.1016/j.biopha.2018.10.088

Hayden, M. S., and Ghosh, S. (2008). Shared Principles in NF-Kb Signaling. Cell 132 (3), 344-362. doi:10.1016/j.cell.2008.01.020

Hayes, J. D., and Dinkova-Kostova, A. T. (2014). The Nrf2 Regulatory Network Provides an Interface between Redox and Intermediary Metabolism. Trends Biochem. Sci. 39 (4), 199-218. doi:10.1016/j.tibs.2014.02.002

Hayes, J. D., McMahon, M., Chowdhry, S., and Dinkova-Kostova, A. T. (2010). Cancer Chemoprevention Mechanisms Mediated through the Keap1-Nrf2 Pathway. Antioxid. Redox Signaling 13 (11), 1713-1748. doi:10.1089/ ars.2010.3221

He, X., Song, Y., Wang, L., and Xu, J. (2020). Protective Effect of Pyrrolidine Dithiocarbamate on Isoniazid/rifampicin-induced L-iver I-njury in R-ats. Mol. Med. Rep. 21 (1), 463-469. doi:10.3892/mmr.2019.10817

Hensley, K. (2010). Neuroinflammation in Alzheimer's Disease: Mechanisms, Pathologic Consequences, and Potential for Therapeutic Manipulation. Jad 21 (1), 1-14. doi:10.3233/JAD-2010-1414

Herpers, B., Wink, S., Fredriksson, L., Di, Z., Hendriks, G., Vrieling, H., et al. (2016). Activation of the Nrf2 Response by Intrinsic Hepatotoxic Drugs Correlates with Suppression of NF-Kb Activation and Sensitizes toward TNFa-Induced Cytotoxicity. Arch. Toxicol. 90 (5), 1163-1179. doi:10.1007/ s00204-015-1536-3

Hoffmann, A., Natoli, G., and Ghosh, G. (2006). Transcriptional Regulation via the NF-Kb Signaling Module. Oncogene 25 (51), 6706-6716. doi:10.1038/ sj.onc. 1209933

Hou, Z., Chen, L., Fang, P., Cai, H., Tang, H., Peng, Y., et al. (2018). Mechanisms of Triptolide-Induced Hepatotoxicity and Protective Effect of Combined Use of Isoliquiritigenin: Possible Roles of Nrf2 and Hepatic Transporters. Front. Pharmacol. 9, 226. doi:10.3389/fphar.2018.00226

Hu, L.-Y., Mi, W.-L., Wu, G.-C., Wang, Y.-Q., and Mao-Ying, Q.-L. (2019). Prevention and Treatment for Chemotherapy-Induced Peripheral Neuropathy: Therapies Based on CIPN Mechanisms. Cn 17 (2), 184-196. doi:10.2174/ 1570159X15666170915143217

Hu, X., Liu, H., Wang, Z., Hu, Z., and Li, L. (2019). miR-200a Attenuated Doxorubicin-Induced Cardiotoxicity through Upregulation of Nrf2 in Mice. Oxidative Med. Cell Longevity 2019, 1-13. doi:10.1155/2019/ 1512326

Huang, X., Wu, J., Liu, X., Wu, H., Fan, J., and Yang, X. (2020). The Protective Role of Nrf2 against Aristolochic Acid-Induced Renal Tubular Epithelial Cell Injury. Toxicol. Mech. Methods 30 (8), 580-589. doi:10.1080/15376516.2020.1795765

Hubbs, A. F., Benkovic, S. A., Miller, D. B., O'Callaghan, J. P., Battelli, L., Schwegler-Berry, D., et al. (2007). Vacuolar Leukoencephalopathy with Widespread Astrogliosis in Mice Lacking Transcription Factor Nrf2. Am. J. Pathol. 170 (6), 2068-2076. doi:10.2353/ajpath.2007.060898

Ibrahim, S. R. M., El-Agamy, D. S., Abdallah, H. M., Ahmed, N., Elkablawy, M. A., and Mohamed, G. A. (2018). Protective Activity of Tovophyllin A, a Xanthone Isolated from Garcinia Mangostana Pericarps, against AcetaminophenInduced Liver Damage: Role of Nrf2 Activation. Food Funct. 9 (6), 3291-3300. doi:10.1039/c8fo00378e

Jangra, A., Kwatra, M., Singh, T., Pant, R., Kushwah, P., Ahmed, S., et al. (2016). Edaravone Alleviates Cisplatin-Induced Neurobehavioral Deficits via Modulation of Oxidative Stress and Inflammatory Mediators in the Rat hippocampus. Eur. J. Pharmacol. 791, 51-61. doi:10.1016/j.ejphar.2016.08.003

Jaul, E., and Barron, J. (2017). Age-Related Diseases and Clinical and Public Health Implications for the 85 Years Old and over Population. Front. Public Health 5 , 335. doi:10.3389/fpubh.2017.00335

Ji, L.-L., Sheng, Y.-C., Zheng, Z.-Y., Shi, L., and Wang, Z.-T. (2015). The Involvement of P62-Keap1-Nrf2 Antioxidative Signaling Pathway and JNK in the protection of Natural Flavonoid Quercetin against Hepatotoxicity. Free Radic. Biol. Med. 85, 12-23. doi:10.1016/j.freeradbiomed.2015.03.035

Jia, Z.-l., Cen, J., Wang, J.-b., Zhang, F., Xia, Q., Wang, X., et al. (2019). Mechanism of Isoniazid-Induced Hepatotoxicity in Zebrafish Larvae: Activation of ROS-
Mediated ERS, Apoptosis and the Nrf2 Pathway. Chemosphere 227, 541-550. doi:10.1016/j.chemosphere.2019.04.026

Jiang, Z.-Y., Chu, H.-X., Xi, M.-Y., Yang, T.-T., Jia, J.-M., Huang, J.-J., et al. (2013). Insight into the Intermolecular Recognition Mechanism between Keapl and IKK $\beta$ Combining Homology Modelling, Protein-Protein Docking, Molecular Dynamics Simulations and Virtual Alanine Mutation. PLoS One 8 (9), e75076. doi:10.1371/journal.pone.0075076

Jin, W., Wang, H., Yan, W., Xu, L., Wang, X., Zhao, X., et al. (2008). Disruption of Nrf2 Enhances Upregulation of Nuclear Factor-Kb Activity, Proinflammatory Cytokines, and Intercellular Adhesion Molecule-1 in the Brain after Traumatic Brain Injury. Mediators Inflamm. 2008, 1-7. doi:10.1155/2008/725174

Joseph Martin, S., and Evan Prince, S. (2017). Comparative Modulation of Levels of Oxidative Stress in the Liver of Anti-Tuberculosis Drug Treated Wistar Rats by Vitamin B12, Beta-Carotene, and Spirulina Fusiformis : Role of NF- $\mathrm{kB}$, iNOS, IL-6, and IL-10. J. Cel. Biochem. 118 (11), 3825-3833. doi:10.1002/jcb.26032

Ju, X., Zhang, H., Zhou, Z., Chen, M., and Wang, Q. (2020). Tumor-associated Macrophages Induce PD-L1 Expression in Gastric Cancer Cells through IL-6 and TNF- $\square$ Signaling. Exp. Cel Res. 396 (2), 112315. doi:10.1016/ j.yexcr.2020.112315

Kalayarasan, S., Prabhu, P. N., Sriram, N., Manikandan, R., Arumugam, M., and Sudhandiran, G. (2009). Diallyl Sulfide Enhances Antioxidants and Inhibits Inflammation through the Activation of Nrf2 against Gentamicin-Induced Nephrotoxicity in Wistar Rats. Eur. J. Pharmacol. 606 (1-3), 162-171. doi:10.1016/j.ejphar.2008.12.055

Kang, H. H., Kim, I. K., Yeo, C. D., Kim, S. W., Lee, H. Y., Im, J. H., et al. (2020). The Effects of Chronic Intermittent Hypoxia in Bleomycin-Induced Lung Injury on Pulmonary Fibrosis via Regulating the NF-kB/Nrf2 Signaling Pathway. Tuberc. Respir. Dis. 83 (Suppl. 1), S63-S74. doi:10.4046/trd.2020.0112

Kastrati, I., Siklos, M. I., Calderon-Gierszal, E. L., El-Shennawy, L., Georgieva, G., Thayer, E. N., et al. (2016). Dimethyl Fumarate Inhibits the Nuclear Factor $\mathrm{\kappa B}$ Pathway in Breast Cancer Cells by Covalent Modification of P65 Protein. J. Biol. Chem. 291 (7), 3639-3647. doi:10.1074/jbc.M115.679704

Kawashiri, T., Miyagi, A., Shimizu, S., Shigematsu, N., Kobayashi, D., and Shimazoe, T. (2018). Dimethyl Fumarate Ameliorates Chemotherapy AgentInduced Neurotoxicity In Vitro. J. Pharmacol. Sci. 137 (2), 202-211. doi:10.1016/j.jphs.2018.06.008

Keleku-Lukwete, N., Suzuki, M., and Yamamoto, M. (2018). An Overview of the Advantages of KEAP1-NRF2 System Activation during Inflammatory Disease Treatment. Antioxid. Redox Signaling 29 (17), 1746-1755. doi:10.1089/ ars.2017.7358

Kensler, T. W., and Wakabayashi, N. (2010). Nrf2: Friend or Foe for Chemoprevention? Carcinogenesis 31 (1), 90-99. doi:10.1093/carcin/bgp231

Khaleel, S. A., Alzokaky, A. A., Raslan, N. A., Alwakeel, A. I., Abd El-Aziz, H. G., and Abd-Allah, A. R. (2017). Lansoprazole Halts Contrast Induced Nephropathy through Activation of Nrf2 Pathway in Rats. ChemicoBiological Interactions 270, 33-40. doi:10.1016/j.cbi.2017.04.010

Khaleel, S. A., Raslan, N. A., Alzokaky, A. A., Ewees, M. G., Ashour, A. A., AbdelHamied, H. E., et al. (2019). Contrast media (Meglumine Diatrizoate) Aggravates Renal Inflammation, Oxidative DNA Damage and Apoptosis in Diabetic Rats Which Is Restored by Sulforaphane through Nrf2/HO-1 Reactivation. Chemico-Biological Interactions 309, 108689. doi:10.1016/ j.cbi.2019.06.002

Kim, H. R., Kim, J. C., Kang, S. Y., Kim, H. O., Park, C. W., and Chung, B. Y. (2021). Rapamycin Alleviates 2,3,7,8-Tetrachlorodibenzo-P-Dioxin-Induced Aggravated Dermatitis in Mice with Imiquimod-Induced Psoriasis-like Dermatitis by Inducing Autophagy. Ijms 22 (8), 3968. doi:10.3390/ ijms 22083968

Kim, S.-W., Lee, H.-K., Shin, J.-H., and Lee, J.-K. (2013). Up-down Regulation of HO-1 and iNOS Gene Expressions by Ethyl Pyruvate via Recruiting P300 to Nrf2 and Depriving it from P65. Free Radic. Biol. Med. 65, 468-476. doi:10.1016/j.freeradbiomed.2013.07.028

Larson, A. M., Polson, J., Fontana, R. J., Davern, T. J., Lalani, E., Hynan, L. S., et al. (2005). Acetaminophen-induced Acute Liver Failure: Results of a United States Multicenter, Prospective Study. Hepatology 42 (6), 1364-1372. doi:10.1002/ hep. 20948

Lastres-Becker, I., Ulusoy, A., Innamorato, N. G., Sahin, G., Rábano, A., Kirik, D., et al. (2012). a-Synuclein Expression and Nrf2 Deficiency Cooperate to Aggravate Protein Aggregation, Neuronal Death and Inflammation in Early- 
Stage Parkinson's Disease. Hum. Mol. Genet. 21 (14), 3173-3192. doi:10.1093/ $\mathrm{hmg} / \mathrm{dds} 143$

Lee, D.-F., Kuo, H.-P., Liu, M., Chou, C.-K., Xia, W., Du, Y., et al. (2009). KEAP1 E3 Ligase-Mediated Downregulation of NF-Kb Signaling by Targeting IKK $\beta$. Mol. Cel 36 (1), 131-140. doi:10.1016/j.molcel.2009.07.025

Lee, I.-C., Kim, S.-H., Lee, S.-M., Baek, H.-S., Moon, C., Kim, S.-H., et al. (2012). Melatonin Attenuates Gentamicin-Induced Nephrotoxicity and Oxidative Stress in Rats. Arch. Toxicol. 86 (10), 1527-1536. doi:10.1007/s00204-0120849-8

Lee, J., Song, K., Hiebert, P., Werner, S., Kim, T.-G., and Kim, Y. S. (2020). Tussilagonone Ameliorates Psoriatic Features in Keratinocytes and Imiquimod-Induced Psoriasis-like Lesions in Mice via NRF2 Activation. J. Invest. Dermatol. 140 (6), 1223-1232. e4. doi:10.1016/j.jid.2019.12.008

Lee, T.-S., Tsai, H.-L., and Chau, L.-Y. (2003). Induction of Heme Oxygenase-1 Expression in Murine Macrophages Is Essential for the Anti-inflammatory Effect of Low Dose 15-Deoxy- $\Delta 12,14$-Prostaglandin J2. J. Biol. Chem. 278 (21), 19325-19330. doi:10.1074/jbc.M300498200

Levine, A. M., Goldstein, M., Meyer, P. R., Forman, S. J., Parker, J. W., PaganiniHill, A., et al. (1985). Heterogeneity of Response and Survival in Diffuse Histiocytic Lymphoma after BACOP Therapy (Bleomycin, Doxorubicin, Cyclophosphamide, Vincristine, Prednisone). Hematol. Oncol. 3 (2), 87-98. doi:10.1002/hon.2900030203

Li, D., Zhang, Y., Pei, X., Liu, X., Dai, C., Li, C., et al. (2020). Molecular Mechanism of Olaquindox-Induced Hepatotoxicity and the Hepatic Protective Role of Curcumin. Food Chem. Toxicol. 145, 111727. doi:10.1016/j.fct.2020.111727

Li, G.-M., Chen, J.-R., Zhang, H.-Q., Cao, X.-Y., Sun, C., Peng, F., et al. (2021). Update on Pharmacological Activities, Security, and Pharmacokinetics of Rhein. Evidence-Based Complement. Altern. Med. 2021, 1-18. doi:10.1155/ 2021/4582412

Li, H.-J., Wu, N.-L., Pu, C.-M., Hsiao, C.-Y., Chang, D.-C., and Hung, C.-F. (2020). Chrysin Alleviates Imiquimod-Induced Psoriasis-like Skin Inflammation and Reduces the Release of CCL20 and Antimicrobial Peptides. Sci. Rep. 10 (1), 2932. doi:10.1038/s41598-020-60050-1

Li, J., Shen, F., Guan, C., Wang, W., Sun, X., Fu, X., et al. (2014). Activation of Nrf2 Protects against Triptolide-Induced Hepatotoxicity. PLoS One 9 (7), e100685. doi:10.1371/journal.pone. 0100685

Li, W., Khor, T. O., Xu, C., Shen, G., Jeong, W.-S., Yu, S., et al. (2008). Activation of Nrf2-Antioxidant Signaling Attenuates NFkB-Inflammatory Response and Elicits Apoptosis. Biochem. Pharmacol. 76 (11), 1485-1489. doi:10.1016/ j.bcp.2008.07.017

Li, X.-J., Jiang, Z.-Z., and Zhang, L.-y. (2014). Triptolide: Progress on Research in Pharmacodynamics and Toxicology. J. Ethnopharmacology 155 (1), 67-79. doi:10.1016/j.jep.2014.06.006

Li, X.-X., Du, F.-Y., Liu, H.-X., Ji, J.-B., and Xing, J. (2015). Investigation of the Active Components in Tripterygium Wilfordii Leading to its Acute Hepatotoxicty and Nephrotoxicity. J. Ethnopharmacology 162, 238-243. doi:10.1016/j.jep.2015.01.004

Li, Y., Gao, M., Yin, L.-H., Xu, L.-N., Qi, Y., Sun, P., et al. (2021). Dioscin Ameliorates Methotrexate-Induced Liver and Kidney Damages via Adjusting miRNA-145-5p-Mediated Oxidative Stress. Free Radic. Biol. Med. 169, 99-109. doi:10.1016/j.freeradbiomed.2021.03.035

Li, Y., Guo, L., Hou, Z., Gong, H., Yan, M., and Zhang, B. (2021). Role of MicroRNA-155 in Triptolide-Induced Hepatotoxicity via the Nrf2dependent Pathway. J. Ethnopharmacology 281, 114489. doi:10.1016/ j.jep.2021.114489

Lin, E.-Y., Chagnaadorj, A., Huang, S.-J., Wang, C.-C., Chiang, Y.-H., and Cheng, C.-W. (2018). Hepatoprotective Activity of the Ethanolic Extract of Polygonum Multiflorum Thunb. Against Oxidative Stress-Induced Liver Injury. EvidenceBased Complement. Altern. Med. 2018, 1-9. doi:10.1155/2018/4130307

Linker, R. A., Lee, D.-H., Ryan, S., van Dam, A. M., Conrad, R., Bista, P., et al. (2011). Fumaric Acid Esters Exert Neuroprotective Effects in Neuroinflammation via Activation of the Nrf2 Antioxidant Pathway. Brain 134 (Pt 3), 678-692. doi:10.1093/brain/awq386

Liu, F. C., Yu, H. P., Chou, A. H., Lee, H. C., and Liao, C. C. (2020). Corilagin Reduces Acetaminophen-Induced Hepatotoxicity through MAPK and NF-Kb Signaling Pathway in a Mouse Model. Am. J. Transl Res. 12 (9), 5597-5607.

Liu, G.-H., Qu, J., and Shen, X. (2008). NF-kB/p65 Antagonizes Nrf2-ARE Pathway by Depriving CBP from Nrf2 and Facilitating Recruitment of HDAC3 to MafK.
Biochim. Biophys. Acta (Bba) - Mol. Cel Res. 1783 (5), 713-727. doi:10.1016/ j.bbamcr.2008.01.002

Liu, T., Zhang, L., Joo, D., and Sun, S.-C. (2017). NF-кB Signaling in Inflammation. Sig Transduct Target. Ther. 2. doi:10.1038/sigtrans.2017.23

Liu, Y., Lu, F., Kang, L., Wang, Z., and Wang, Y. (2017). Pirfenidone Attenuates Bleomycin-Induced Pulmonary Fibrosis in Mice by Regulating Nrf2/Bach1 Equilibrium. BMC Pulm. Med. 17 (1), 63. doi:10.1186/s12890-017-0405-7

Liu, Z.-g. (2005). Molecular Mechanism of TNF Signaling and beyond. Cell Res 15 (1), 24-27. doi:10.1038/sj.cr.7290259

Lv, H., Hong, L., Tian, Y., Yin, C., Zhu, C., and Feng, H. (2019). Corilagin Alleviates Acetaminophen-Induced Hepatotoxicity via Enhancing the AMPK/GSK3 $\beta$ Nrf2 Signaling Pathway. Cell Commun Signal 17 (1), 2. doi:10.1186/s12964018-0314-2

Lv, H., Xiao, Q., Zhou, J., Feng, H., Liu, G., and Ci, X. (2018). Licochalcone A Upregulates Nrf2 Antioxidant Pathway and Thereby Alleviates Acetaminophen-Induced Hepatotoxicity. Front. Pharmacol. 9, 147. doi:10.3389/fphar.2018.00147

Lv, H., Zhu, C., Wei, W., Lv, X., Yu, Q., Deng, X., et al. (2020). Enhanced Keap1Nrf2/Trx-1 axis by Daphnetin Protects against Oxidative Stress-Driven Hepatotoxicity via Inhibiting ASK1/JNK and Txnip/NLRP3 Inflammasome Activation. Phytomedicine 71, 153241. doi:10.1016/j.phymed.2020.153241

Lv, Z., Shen, J., Gao, X., Ruan, Y., Ling, J., Sun, R., et al. (2021). Herbal Formula Huangqi Guizhi Wuwu Decoction Attenuates Paclitaxel-Related Neurotoxicity via Inhibition of Inflammation and Oxidative Stress. Chin. Med. 16 (1), 76. doi:10.1186/s13020-021-00488-1

Ma, Q. (2013). Role of Nrf2 in Oxidative Stress and Toxicity. Annu. Rev. Pharmacol. Toxicol. 53, 401-426. doi:10.1146/annurev-pharmtox-011112140320

Ma, W.-h., Li, M., Ma, H.-f., Li, W., Liu, L., Yin, Y., et al. (2020). Protective Effects of GHK-Cu in Bleomycin-Induced Pulmonary Fibrosis via Anti-oxidative Stress and Anti-inflammation Pathways. Life Sci. 241, 117139. doi:10.1016/ j.lfs.2019.117139

Mahmoud, A. M., Germoush, M. O., Al-Anazi, K. M., Mahmoud, A. H., Farah, M. A., and Allam, A. A. (2018). Commiphora Molmol Protects against Methotrexate-Induced Nephrotoxicity by Up-Regulating Nrf2/ARE/HO-1 Signaling. Biomed. Pharmacother. 106, 499-509. doi:10.1016/ j.biopha.2018.06.171

Mahmoud, Y. I. (2017). Kiwi Fruit (Actinidia Deliciosa) Ameliorates GentamicinInduced Nephrotoxicity in Albino Mice via the Activation of Nrf2 and the Inhibition of NF-Kb (Kiwi \& Gentamicin-Induced Nephrotoxicity). Biomed. Pharmacother. 94, 206-218. doi:10.1016/j.biopha.2017.07.079

Malekinejad, H., Ahsan, S., Delkhosh-Kasmaie, F., Cheraghi, H., RezaeiGolmisheh, A., and Janbaz-Acyabar, H. (2016). Cardioprotective Effect of Royal Jelly on Paclitaxel-Induced Cardio-Toxicity in Rats. Iran J. Basic Med. Sci. 19 (2), 221-227.

Mattson, M. P., and Camandola, S. (2001). NF-kB in Neuronal Plasticity and Neurodegenerative Disorders. J. Clin. Invest. 107 (3), 247-254. doi:10.1172/ JCI11916

Melli, G., Jack, C., Lambrinos, G. L., Ringkamp, M., and Höke, A. (2006). Erythropoietin Protects Sensory Axons against Paclitaxel-Induced Distal Degeneration. Neurobiol. Dis. 24 (3), 525-530. doi:10.1016/j.nbd.2006.08.014

Meng, Y.-k., Li, C.-y., Li, R.-y., He, L.-z., Cui, H.-r., Yin, P., et al. (2017). Cis-stilbene Glucoside in Polygonum Multiflorum Induces Immunological Idiosyncratic Hepatotoxicity in LPS-Treated Rats by Suppressing PPAR- $\gamma$. Acta Pharmacol. Sin 38 (10), 1340-1352. doi:10.1038/aps.2017.32

Minelli, A., Grottelli, S., Mierla, A., Pinnen, F., Cacciatore, I., and Bellezza, I. (2012). Cyclo(His-Pro) Exerts Anti-inflammatory Effects by Modulating NF-Kb and Nrf2 Signalling. Int. J. Biochem. Cel Biol. 44 (3), 525-535. doi:10.1016/ j.biocel.2011.12.006

Namikawa, K., Asakura, M., Minami, T., Okazaki, Y., Kadota, E., and Hashimoto, S. (2000). Toxicity of Cisplatin to the central Nervous System of Male Rabbits. Bter 74 (3), 223-236. doi:10.1385/BTER:74:3:223

Nash, K., Hafeez, A., and Hou, S. (2002). Hospital-acquired Renal Insufficiency. Am. J. Kidney Dis. 39 (5), 930-936. doi:10.1053/ajkd.2002.32766

Nestle, F. O., Kaplan, D. H., and Barker, J. (2009). Psoriasis. N. Engl. J. Med. 361 (5), 496-509. doi:10.1056/NEJMra0804595

Niccoli, T., and Partridge, L. (2012). Ageing as a Risk Factor for Disease. Curr. Biol. 22 (17), R741-R752. doi:10.1016/j.cub.2012.07.024 
Niu, H.-M., Guo, L.-Q., Qiao, Y.-H., and Jiao, H.-Y. (2021). MiR-429 Prohibited $\mathrm{NF}-\mathrm{Kb}$ Signalling to Alleviate Contrast-Induced Acute Kidney Injury via Targeting PDCD4. Autoimmunity 54 (5), 243-253. doi:10.1080/ 08916934.2021 .1919878

Octavia, Y., Tocchetti, C. G., Gabrielson, K. L., Janssens, S., Crijns, H. J., and Moens, A. L. (2012). Doxorubicin-induced Cardiomyopathy: from Molecular Mechanisms to Therapeutic Strategies. J. Mol. Cell Cardiol. 52 (6), 1213-1225. doi:10.1016/j.yjmcc.2012.03.006

Ogawa, T., Ishitsuka, Y., Inoue, S., Nakamura, Y., Saito, A., Okiyama, N., et al. (2020). Nuclear Factor Erythroid 2-Related Factor 2 (Nrf2) Regulates Epidermal Keratinization under Psoriatic Skin Inflammation. Am. J. Pathol. 190 (3), 577-585. doi:10.1016/j.jpath.2019.10.022

Pan, H., Wang, H., Wang, X., Zhu, L., and Mao, L. (2012). The Absence of Nrf2 Enhances NF-B-dependent Inflammation Following Scratch Injury in Mouse Primary Cultured Astrocytes. Mediators Inflamm. 2012, 1-9. doi:10.1155/2012/ 217580

Pan, X., Wu, X., Yan, D., Peng, C., Rao, C., and Yan, H. (2018). Acrylamideinduced Oxidative Stress and Inflammatory Response Are Alleviated by N-Acetylcysteine in PC12 Cells: Involvement of the Crosstalk between Nrf2 and NF-Kb Pathways Regulated by MAPKs. Toxicol. Lett. 288, 55-64. doi:10.1016/j.toxlet.2018.02.002

Park, C. H., Lee, A. Y., Kim, J. H., Seong, S. H., Jang, G. Y., Cho, E. J., et al. (2018). Protective Effect of Safflower Seed on Cisplatin-Induced Renal Damage in Mice via Oxidative Stress and Apoptosis-Mediated Pathways. Am. J. Chin. Med. 46 (1), 157-174. doi:10.1142/S0192415X1850009X

Peng, C., Ouyang, Y., Lu, N., and Li, N. (2020). The NF-Kb Signaling Pathway, the Microbiota, and Gastrointestinal Tumorigenesis: Recent Advances. Front. Immunol. 11, 1387. doi:10.3389/fimmu.2020.01387

Qi, W., Boliang, W., Xiaoxi, T., Guoqiang, F., Jianbo, X., and Gang, W. (2020). Cardamonin Protects against Doxorubicin-Induced Cardiotoxicity in Mice by Restraining Oxidative Stress and Inflammation Associated with Nrf2 Signaling. Biomed. Pharmacother. 122, 109547. doi:10.1016/ j.biopha.2019.109547

Qin, X., Meghana, K., Sowjanya, N. L., Sushma, K. R., Krishna, C. G., Manasa, J., et al. (2019). Embelin Attenuates Cisplatin-induced Nephrotoxicity: Involving Inhibition of Oxidative Stress and Inflammation in Addition with Activation of Nrf-2/Ho-1 Pathway. Biofactors 45 (3), 471-478. doi:10.1002/biof.1502

Qu, Z., Sun, J., Zhang, W., Yu, J., and Zhuang, C. (2020). Transcription Factor NRF2 as a Promising Therapeutic Target for Alzheimer's Disease. Free Radic. Biol. Med. 159, 87-102. doi:10.1016/j.freeradbiomed.2020.06.028

Rada, P., Pardo, V., Mobasher, M. A., García-Martínez, I., Ruiz, L., GonzálezRodríguez, Á., et al. (2018). SIRT1 Controls Acetaminophen Hepatotoxicity by Modulating Inflammation and Oxidative Stress. Antioxid. Redox Signaling 28 (13), 1187-1208. doi:10.1089/ars.2017.7373

Rada, P., Rojo, A. I., Chowdhry, S., McMahon, M., Hayes, J. D., and Cuadrado, A. (2011). SCF/-TrCP Promotes Glycogen Synthase Kinase 3-Dependent Degradation of the Nrf2 Transcription Factor in a Keap1-independent Manner. Mol. Cell Biol. 31 (6), 1121-1133. doi:10.1128/MCB.01204-10

Ramsey, C. P., Glass, C. A., Montgomery, M. B., Lindl, K. A., Ritson, G. P., Chia, L. A., et al. (2007). Expression of Nrf2 in Neurodegenerative Diseases. J. Neuropathol. Exp. Neurol. 66 (1), 75-85. doi:10.1097/nen.0b013e31802d6da9

Rushworth, S. A., MacEwan, D. J., and O'Connell, M. A. (2008). Lipopolysaccharide-Induced Expression of NAD(P)H:Quinone Oxidoreductase 1 and Heme Oxygenase-1 Protects against Excessive Inflammatory Responses in Human Monocytes. J. Immunol. 181 (10), 6730-6737. doi:10.4049/jimmunol.181.10.6730

Saeedi, B. J., Liu, K. H., Owens, J. A., Hunter-Chang, S., Camacho, M. C., Eboka, R. U., et al. (2020). Gut-Resident Lactobacilli Activate Hepatic Nrf2 and Protect against Oxidative Liver Injury. Cel Metab. 31 (5), 956-968. e5. doi:10.1016/ j.cmet.2020.03.006

Sahu, R., Dua, T. K., Das, S., De Feo, V., and Dewanjee, S. (2019). Wheat Phenolics Suppress Doxorubicin-Induced Cardiotoxicity via Inhibition of Oxidative Stress, MAP Kinase Activation, NF-Kb Pathway, PI3K/Akt/mTOR Impairment, and Cardiac Apoptosis. Food Chem. Toxicol. 125, 503-519. doi:10.1016/j.fct.2019.01.034

Sandberg, M., Patil, J., D’Angelo, B., Weber, S. G., and Mallard, C. (2014). NRF2regulation in Brain Health and Disease: Implication of Cerebral Inflammation. Neuropharmacology 79, 298-306. doi:10.1016/j.neuropharm.2013.11.004
Sangaraju, R., Alavala, S., Nalban, N., Jerald, M. K., and Sistla, R. (2021). Galangin Ameliorates Imiquimod-Induced Psoriasis-like Skin Inflammation in BALB/c Mice via Down Regulating NF-Kb and Activation of Nrf2 Signaling Pathways. Int. Immunopharmacology 96, 107754. doi:10.1016/j.intimp.2021.107754

Sanjay, S., Girish, C., Toi, P. C., and Bobby, Z. (2021). Gallic Acid Attenuates Isoniazid and Rifampicin-Induced Liver Injury by Improving Hepatic Redox Homeostasis through Influence on Nrf2 and NF-Kb Signalling Cascades in Wistar Rats. J. Pharm. Pharmacol. 73 (4), 473-486. doi:10.1093/jpp/rgaa048

Sanjay, S., Girish, C., Toi, P. C., and Bobby, Z. (2021). Quercetin Modulates NRF2 and NF-Kb/tlr-4 Pathways to Protect against Isoniazid- and RifampicinInduced Hepatotoxicity In Vivo. Can. J. Physiol. Pharmacol. 99 (9), 952-963. doi:10.1139/cjpp-2021-0008

Saritemur, M., Un, H., Cadirci, E., Karakus, E., Akpinar, E., Halici, Z., et al. (2015). Tnf- $\alpha$ Inhibition by Infliximab as a New Target for the Prevention of GlycerolContrast-Induced Nephropathy. Environ. Toxicol. Pharmacol. 39 (2), 577-588. doi:10.1016/j.etap.2015.01.002

Schwaninger, M., Sallmann, S., Petersen, N., Schneider, A., Prinz, S., Libermann, T. A., et al. (1999). Bradykinin Induces Interleukin-6 Expression in Astrocytes through Activation of Nuclear Factor-Kb. J. Neurochem. 73 (4), 1461-1466. doi:10.1046/j.1471-4159.1999.0731461.x

Selkoe, D. J. (2001). Clearing the Brain's Amyloid Cobwebs. Neuron 32 (2), 177-180. doi:10.1016/s0896-6273(01)00475-5

Senftleben, U., Cao, Y., Xiao, G., Greten, F. R., Krähn, G., Bonizzi, G., et al. (2001). Activation by IKKa of a Second, Evolutionary Conserved, NF-Kb Signaling Pathway. Science 293 (5534), 1495-1499. doi:10.1126/science.1062677

Shaikh, S. B., and Prabhakar Bhandary, Y. (2020). Effect of Curcumin on IL-17A Mediated Pulmonary AMPK Kinase/cyclooxygenase-2 Expressions via Activation of NFkB in Bleomycin-Induced Acute Lung Injury In Vivo. Int. Immunopharmacology 85, 106676. doi:10.1016/j.intimp.2020.106676

Shalaby, Y. M., Menze, E. T., Azab, S. S., and Awad, A. S. (2019). Involvement of $\mathrm{Nrf2/HO}-1$ Antioxidant Signaling and NF-Kb Inflammatory Response in the Potential Protective Effects of Vincamine against Methotrexate-Induced Nephrotoxicity in Rats: Cross Talk between Nephrotoxicity and Neurotoxicity. Arch. Toxicol. 93 (5), 1417-1431. doi:10.1007/s00204-01902429-2

Sherif, I. O., Al-Mutabagani, L. A., and Sarhan, O. M. (2020). Ginkgo Biloba Extract Attenuates Methotrexate-Induced Testicular Injury in Rats: Cross-Talk between Oxidative Stress, Inflammation, Apoptosis, and miRNA-29a Expression. Integr. Cancer Ther. 19, 153473542096981. doi:10.1177/ 1534735420969814

Siggers, T., Chang, A. B., Teixeira, A., Wong, D., Williams, K. J., Ahmed, B., et al. (2011). Principles of Dimer-specific Gene Regulation Revealed by a Comprehensive Characterization of NF-Kb Family DNA Binding. Nat. Immunol. 13 (1), 95-102. doi:10.1038/ni.2151

Sivandzade, F., Prasad, S., Bhalerao, A., and Cucullo, L. (2019). NRF2 and NF-Қb Interplay in Cerebrovascular and Neurodegenerative Disorders: Molecular Mechanisms and Possible Therapeutic Approaches. Redox Biol. 21, 101059. doi:10.1016/j.redox.2018.11.017

Skibinski, G., Hwang, V., Ando, D. M., Daub, A., Lee, A. K., Ravisankar, A., et al. (2017). Nrf2 Mitigates LRRK2- and $\alpha$-synuclein-induced Neurodegeneration by Modulating Proteostasis. Proc. Natl. Acad. Sci. USA 114 (5), 1165-1170. doi:10.1073/pnas.1522872114

Song, M.-K., Lee, J.-H., Ryoo, I.-g., Lee, S.-h., Ku, S.-K., and Kwak, M.-K. (2019). Bardoxolone Ameliorates TGF-B1-Associated Renal Fibrosis through Nrf2/ Smad7 Elevation. Free Radic. Biol. Med. 138, 33-42. doi:10.1016/ j.freeradbiomed.2019.04.033

Song, M.-Y., Kim, E.-K., Moon, W.-S., Park, J.-W., Kim, H.-J., So, H.-S., et al. (2009). Sulforaphane Protects against Cytokine- and Streptozotocin-Induced $\beta$ cell Damage by Suppressing the NF-Kb Pathway. Toxicol. Appl. Pharmacol. 235 (1), 57-67. doi:10.1016/j.taap.2008.11.007

Souza, T. M., Kleinjans, J. C. S., and Jennen, D. G. J. (2017). Dose and Time Dependencies in Stress Pathway Responses during Chemical Exposure: Novel Insights from Gene Regulatory Networks. Front. Genet. 8, 142. doi:10.3389/ fgene.2017.00142

Sun, H.-J., Leng, B., Wu, Z.-Y., and Bian, J.-S. (2020). Polysulfide and Hydrogen Sulfide Ameliorate Cisplatin-Induced Nephrotoxicity and Renal Inflammation through Persulfidating STAT3 and IKK $\beta$. Ijms 21 (20), 7805. doi:10.3390/ ijms 21207805 
Sun, S.-C., and Ley, S. C. (2008). New Insights into NF-Kb Regulation and Function. Trends Immunol. 29 (10), 469-478. doi:10.1016/j.it.2008.07.003

Sun, S.-C., and Liu, Z.-G. (2011). A Special Issue on NF-Kb Signaling and Function. Cel Res 21 (1), 1-2. doi:10.1038/cr.2011.1

Sun, S.-C. (2011). Non-canonical NF-Kb Signaling Pathway. Cel Res 21 (1), 71-85. doi: $10.1038 /$ cr.2010.177

Sun, S.-C. (2012). The Noncanonical NF-Kb Pathway. Immunol. Rev. 246 (1), 125-140. doi:10.1111/j.1600-065X.2011.01088.x

Suzuki, T., Motohashi, H., and Yamamoto, M. (2013). Toward Clinical Application of the Keap1-Nrf2 Pathway. Trends Pharmacol. Sci. 34 (6), 340-346. doi:10.1016/j.tips.2013.04.005

Taghizadeh, F., Hosseinimehr, S. J., Zargari, M., Karimpour Malekshah, A., and Talebpour Amiri, F. B. (2020). Gliclazide Attenuates Cisplatin-induced Nephrotoxicity through inhibitingNF-kBand Caspase-3 Activity. IUBMB Life 72 (9), 2024-2033. doi:10.1002/iub.2342

Tang, H., Gao, L., Mao, J., He, H., Liu, J., Cai, X., et al. (2016). Salidroside Protects against Bleomycin-Induced Pulmonary Fibrosis: Activation of Nrf2Antioxidant Signaling, and Inhibition of NF-Kb and TGF- $\beta 1 /$ Smad- $2 /-3$ Pathways. Cell Stress and Chaperones 21 (2), 239-249. doi:10.1007/s12192015-0654-4

Tonelli, C., Chio, I. I. C., II., and Tuveson, D. A. (2018). Transcriptional Regulation by Nrf2. Antioxid. Redox Signaling 29 (17), 1727-1745. doi:10.1089/ ars.2017.7342

Tong, K. I., Kobayashi, A., Katsuoka, F., and Yamamoto, M. (2006). Two-site Substrate Recognition Model for the Keap1-Nrf2 System: a Hinge and Latch Mechanism. Biol. Chem. 387 (10-11), 1311-1320. doi:10.1515/BC.2006.164

Tsai, K.-d., Chen, W., Wang, S.-H., Hsiao, Y.-W., Chi, J.-Y., Wu, H.-Y., et al. (2014). Downregulation of Connective Tissue Growth Factor by LPS/IFN- $\gamma$ induced Nitric Oxide Is Reversed by Aristolochic Acid Treatment in Glomerular Mesangial Cells via STAT-1a and NF-Kb Signaling. ChemicoBiological Interactions 210, 86-95. doi:10.1016/j.cbi.2013.12.017

Tugcu, V., Ozbek, E., Tasci, A. I., Kemahli, E., Somay, A., Bas, M., et al. (2006). Selective Nuclear Factor $\mathrm{k}-\mathrm{B}$ Inhibitors, Pyrolidium Dithiocarbamate and Sulfasalazine, Prevent the Nephrotoxicity Induced by Gentamicin. BJU Int. 98 (3), 680-686. doi:10.1111/j.1464-410X.2006.06321.x

Un, H., Ugan, R. A., Kose, D., Bayir, Y., Cadirci, E., Selli, J., et al. (2020). A Novel Effect of Aprepitant: Protection for Cisplatin-Induced Nephrotoxicity and Hepatotoxicity. Eur. J. Pharmacol. 880, 173168. doi:10.1016/ j.ejphar.2020.173168

Valcarcel-Ares, M. N., Gautam, T., Warrington, J. P., Bailey-Downs, L., Sosnowska, D., de Cabo, R., et al. (2012). Disruption of Nrf2 Signaling Impairs Angiogenic Capacity of Endothelial Cells: Implications for Microvascular Aging. Journals Gerontol. Ser. A: Biol. Sci. Med. Sci. 67 (8), 821-829. doi:10.1093/gerona/glr229

Vanherweghem, J.-L., Tielemans, C., Abramowicz, D., Depierreux, M., VanhaelenFastre, R., Vanhaelen, M., et al. (1993). Rapidly Progressive Interstitial Renal Fibrosis in Young Women: Association with Slimming Regimen Including Chinese Herbs. The Lancet 341 (8842), 387-391. doi:10.1016/0140-6736(93) 92984-2

Varga, Z. V., Ferdinandy, P., Liaudet, L., and Pacher, P. (2015). Drug-induced Mitochondrial Dysfunction and Cardiotoxicity. Am. J. Physiology-Heart Circulatory Physiol. 309 (9), H1453-H1467. doi:10.1152/ajpheart.00554.2015

Verma, A. K., Yadav, A., Dewangan, J., Singh, S. V., Mishra, M., Singh, P. K., et al. (2015). Isoniazid Prevents Nrf2 Translocation by Inhibiting ERK1 Phosphorylation and Induces Oxidative Stress and Apoptosis. Redox Biol. 6, 80-92. doi:10.1016/j.redox.2015.06.020

Verma, A. K., Yadav, A., Singh, S. V., Mishra, P., and Rath, S. K. (2018). Isoniazid Induces Apoptosis: Role of Oxidative Stress and Inhibition of Nuclear Translocation of Nuclear Factor (Erythroid-derived 2)-like 2 (Nrf2). Life Sci. 199, 23-33. doi:10.1016/j.lfs.2018.02.037

von Otter, M., Landgren, S., Nilsson, S., Celojevic, D., Bergström, P., Håkansson, A., et al. (2010). Association of Nrf2-Encoding NFE2L2 Haplotypes with Parkinson's Disease. BMC Med. Genet. 11, 36. doi:10.1186/1471-2350-11-36

von Otter, M., Landgren, S., Nilsson, S., Zetterberg, M., Celojevic, D., Bergström, P., et al. (2010). Nrf2-encoding NFE2L2 Haplotypes Influence Disease Progression but Not Risk in Alzheimer's Disease and Age-Related Cataract. Mech. Ageing Dev. 131 (2), 105-110. doi:10.1016/j.mad.2009.12.007

Wang, C., Hu, N.-H., Yu, L.-Y., Gong, L.-H., Dai, X.-Y., Peng, C., et al. (2020). 2,3,5,4'-tetrahydroxystilbence-2-O- $\beta$-D-glucoside Attenuates Hepatic Steatosis via IKK $\beta / \mathrm{NF}-\mathrm{Kb}$ and Keap1-Nrf2 Pathways in Larval Zebrafish. Biomed. Pharmacother. 127, 110138. doi:10.1016/j.biopha.2020.110138

Wang, J., Luo, W., Li, B., Lv, J., Ke, X., Ge, D., et al. (2018). Sagittaria Sagittifolia Polysaccharide Protects against Isoniazid- and Rifampicin-Induced Hepatic Injury via Activation of Nuclear Factor E2-Related Factor 2 Signaling in Mice. J. Ethnopharmacology 227, 237-245. doi:10.1016/j.jep.2018.09.002

Wang, L., Wei, W., Xiao, Q., Yang, H., and Ci, X. (2019). Farrerol Ameliorates APAP-Induced Hepatotoxicity via Activation of Nrf2 and Autophagy. Int. J. Biol. Sci. 15 (4), 788-799. doi:10.7150/ijbs.30677

Wang, V. Y.-F., Huang, W., Asagiri, M., Spann, N., Hoffmann, A., Glass, C., et al. (2012). The Transcriptional Specificity of NF-Kb Dimers Is Coded within the кB DNA Response Elements. Cel Rep. 2 (4), 824-839. doi:10.1016/ j.celrep.2012.08.042

Wang, X. J., Li, Y., Luo, L., Wang, H., Chi, Z., Xin, A., et al. (2014). Oxaliplatin Activates the Keap1/Nrf2 Antioxidant System Conferring protection against the Cytotoxicity of Anticancer Drugs. Free Radic. Biol. Med. 70, 68-77. doi:10.1016/j.freeradbiomed.2014.02.010

Wang, Z., Hao, W., Hu, J., Mi, X., Han, Y., Ren, S., et al. (2019). Maltol Improves APAP-Induced Hepatotoxicity by Inhibiting Oxidative Stress and Inflammation Response via NF-Kb and PI3K/Akt Signal Pathways. Antioxidants 8 (9), 395. doi:10.3390/antiox8090395

Wei, C.-B., Tao, K., Jiang, R., Zhou, L.-D., Zhang, Q.-H., and Yuan, C.-S. (2017). Quercetin Protects Mouse Liver against Triptolide-Induced Hepatic Injury by Restoring Th17/Treg Balance through Tim-3 and TLR4-MyD88-NF-Kb Pathway. Int. Immunopharmacology 53, 73-82. doi:10.1016/ j.intimp.2017.09.026

Wu, C.-T., Deng, J.-S., Huang, W.-C., Shieh, P.-C., Chung, M.-I., and Huang, G.-J. (2019). Salvianolic Acid C against Acetaminophen-Induced Acute Liver Injury by Attenuating Inflammation, Oxidative Stress, and Apoptosis through Inhibition of the Keap1/Nrf2/HO-1 Signaling. Oxidative Med. Cell Longevity 2019, 1-13. doi:10.1155/2019/9056845

Wu, J., Liu, X., Fan, J., Chen, W., Wang, J., Zeng, Y., et al. (2014). Bardoxolone Methyl (BARD) Ameliorates Aristolochic Acid (AA)-induced Acute Kidney Injury through Nrf2 Pathway. Toxicology 318, 22-31. doi:10.1016/ j.tox.2014.01.008

Xi, C., Peng, S., Wu, Z., Zhou, Q., and Zhou, J. (2017). Toxicity of Triptolide and the Molecular Mechanisms Involved. Biomed. Pharmacother. 90, 531-541. doi:10.1016/j.biopha.2017.04.003

Xiao, G., Harhaj, E. W., and Sun, S.-C. (2001). NF-кB-Inducing Kinase Regulates the Processing of NF-Kb2 P100. Mol. Cel 7 (2), 401-409. doi:10.1016/s10972765(01)00187-3

Xu, A., Deng, F., Chen, Y., Kong, Y., Pan, L., Liao, Q., et al. (2020). NF-kB Pathway Activation during Endothelial-To-Mesenchymal Transition in a Rat Model of Doxorubicin-Induced Cardiotoxicity. Biomed. Pharmacother. 130, 110525. doi:10.1016/j.biopha.2020.110525

Yang, L., Xing, G., Wang, L., Wu, Y., Li, S., Xu, G., et al. (2015). Acute Kidney Injury in China: a Cross-Sectional Survey. The Lancet 386 (10002), 1465-1471. doi:10.1016/s0140-6736(15)00344-x

Yang, R., Song, C., Chen, J., Zhou, L., Jiang, X., Cao, X., et al. (2020). Limonin Ameliorates Acetaminophen-Induced Hepatotoxicity by Activating Nrf2 Antioxidative Pathway and Inhibiting NF-Kb Inflammatory Response via Upregulating Sirt1. Phytomedicine 69, 153211. doi:10.1016/ j.phymed.2020.153211

Yardım, A., Kandemir, F. M., Çomaklı, S., Özdemir, S., Caglayan, C., Kucukler, S., et al. (2021). Protective Effects of Curcumin against Paclitaxel-Induced Spinal Cord and Sciatic Nerve Injuries in Rats. Neurochem. Res. 46 (2), 379-395. doi:10.1007/s11064-020-03174-0

Yardim, A., Kandemir, F. M., Ozdemir, S., Kucukler, S., Comakli, S., Gur, C., et al. (2020). Quercetin Provides protection against the Peripheral Nerve Damage Caused by Vincristine in Rats by Suppressing Caspase 3, NF-Kb, ATF-6 Pathways and Activating Nrf2, Akt Pathways. Neurotoxicology 81, 137-146. doi:10.1016/j.neuro.2020.10.001

Yarmohammadi, F., Rezaee, R., and Karimi, G. (2021). Natural Compounds against Doxorubicin-induced Cardiotoxicity: A Review on the Involvement of Nrf2/ARE Signaling Pathway. Phytotherapy Res. 35 (3), 1163-1175. doi:10.1002/ptr.6882

Yehia, R., Saleh, S., El Abhar, H., Saad, A. S., and Schaalan, M. (2019). L-carnosine Protects against Oxaliplatin-Induced Peripheral Neuropathy in Colorectal 
Cancer Patients: A Perspective on Targeting Nrf-2 and NF-Kb Pathways. Toxicol. Appl. Pharmacol. 365, 41-50. doi:10.1016/j.taap.2018.12.015

Yen, H.-C., Chang, H.-M., Majima, H. J., Chen, F.-Y., and Li, S.-H. (2005). Levels of Reactive Oxygen Species and Primary Antioxidant Enzymes in WI38 versus Transformed WI38 Cells Following Bleomcyin Treatment. Free Radic. Biol. Med. 38 (7), 950-959. doi:10.1016/j.freeradbiomed.2004.12.022

Younis, N. N., Elsherbiny, N. M., Shaheen, M. A., and Elseweidy, M. M. (2020). Modulation of NADPH Oxidase and Nrf2/HO-1 Pathway by Vanillin in Cisplatin-Induced Nephrotoxicity in Rats. J. Pharm. Pharmacol. 72 (11), 1546-1555. doi:10.1111/jphp.13340

Younis, N. S., Elsewedy, H. S., Soliman, W. E., Shehata, T. M., and Mohamed, M. E. (2021). Geraniol Isolated from Lemon Grass to Mitigate Doxorubicin-Induced Cardiotoxicity through Nrf2 and NF-Kb Signaling. Chemico-Biological Interactions 347, 109599. doi:10.1016/j.cbi.2021.109599

Yu, J., Xie, J., Mao, X.-j., Wang, M.-j., Li, N., Wang, J., et al. (2011). Hepatoxicity of Major Constituents and Extractions of Radix Polygoni Multiflori and Radix Polygoni Multiflori Praeparata. J. Ethnopharmacology 137 (3), 1291-1299. doi:10.1016/j.jep.2011.07.055

Yu, W., Zhao, J., Li, W., Zheng, Y., Zhu, J., Liu, J., et al. (2020). 2,3,5,4'Tetrahydroxystilbene-2-O- $\beta$-d-glucoside Alleviated the Acute Hepatotoxicity and DNA Damage in Diethylnitrosamine-Contaminated Mice. Life Sci. 243, 117274. doi:10.1016/j.lfs.2020.117274

Yu, X., Meng, X., Xu, M., Zhang, X., Zhang, Y., Ding, G., et al. (2018). Celastrol Ameliorates Cisplatin Nephrotoxicity by Inhibiting NF-Kb and Improving Mitochondrial Function. EBioMedicine 36, 266-280. doi:10.1016/ j.ebiom.2018.09.031

Yuan, Z., Yuan, Z., Hasnat, M., Zhang, H., Liang, P., Sun, L., et al. (2020). A New Perspective of Triptolide-Associated Hepatotoxicity: the Relevance of NF- B and NF- B-Mediated Cellular FLICE-Inhibitory Protein. Acta Pharmaceutica Sinica B 10 (5), 861-877. doi:10.1016/j.apsb.2020.02.009

Yue, R., Zuo, C., Zeng, J., Su, B., Tao, Y., Huang, S., et al. (2017). Atorvastatin Attenuates Experimental Contrast-Induced Acute Kidney Injury: a Role for TLR4/MyD88 Signaling Pathway. Ren. Fail. 39 (1), 643-651. doi:10.1080/ 0886022X.2017.1361838

Zagar, T. M., Cardinale, D. M., and Marks, L. B. (2016). Breast Cancer TherapyAssociated Cardiovascular Disease. Nat. Rev. Clin. Oncol. 13 (3), 172-184. doi:10.1038/nrclinonc.2015.171

Zhang, Q., Zhao, Y., Talukder, M., Han, Y., Zhang, C., Li, X.-N., et al. (2019). Di(2ethylhexyl) Phthalate Induced Hepatotoxicity in Quail (Coturnix japonica) via Modulating the Mitochondrial Unfolded Protein Response and NRF2 Mediated Antioxidant Defense. Sci. Total Environ. 651 (Pt 1), 885-894. doi:10.1016/ j.scitotenv.2018.09.211

Zhang, X., Wang, T., Yang, Y., Li, R., Chen, Y., Li, R., et al. (2020). Tanshinone IIA Attenuates Acetaminophen-Induced Hepatotoxicity through HOTAIR-Nrf2Mrp2/4 Signaling Pathway. Biomed. Pharmacother. 130, 110547. doi:10.1016/ j.biopha.2020.110547

Zhao, B., Barrera, L. A., Ersing, I., Willox, B., Schmidt, S. C. S., Greenfeld, H., et al. (2014). The NF-Kb Genomic Landscape in Lymphoblastoid B Cells. Cel Rep. 8 (5), 1595-1606. doi:10.1016/j.celrep.2014.07.037
Zhao, F., Feng, L.-X., Liu, Q., Wang, H.-S., Tang, C.-Y., Cheng, W., et al. (2020). Stanniocalcin-1 Alleviates Contrast-Induced Acute Kidney Injury by Regulating Mitochondrial Quality Control via the Nrf2 Pathway. Oxidative Med. Cell Longevity 2020, 1-17. doi:10.1155/2020/1898213

Zhao, L., Qi, Y., Xu, L., Tao, X., Han, X., Yin, L., et al. (2018). MicroRNA-140-5p Aggravates Doxorubicin-Induced Cardiotoxicity by Promoting Myocardial Oxidative Stress via Targeting Nrf2 and Sirt2. Redox Biol. 15, 284-296. doi:10.1016/j.redox.2017.12.013

Zhao, M., Lewis Wang, F. S., Hu, X., Chen, F., and Chan, H. M. (2017). Acrylamideinduced Neurotoxicity in Primary Astrocytes and Microglia: Roles of the Nrf2ARE and NF-Kb Pathways. Food Chem. Toxicol. 106 (Pt A), 25-35. doi:10.1016/ j.fct.2017.05.007

Zhao, Y.-Y., Wang, H.-L., Cheng, X.-L., Wei, F., Bai, X., Lin, R.-C., et al. (2015). Metabolomics Analysis Reveals the Association between Lipid Abnormalities and Oxidative Stress, Inflammation, Fibrosis and Nrf2 Dysfunction in Aristolochic Acid-Induced Nephropathy. Sci. Rep. 5, 12936. doi:10.1038/ srep12936

Zhou, F., Zhu, Z., Gao, J., Yang, C., Wen, L., Liu, L., et al. (2018). NFKB1 Mediates Th1/Th17 Activation in the Pathogenesis of Psoriasis. Cell Immunol. 331, 16-21. doi:10.1016/j.cellimm.2018.04.016

Zhou, Q., Wang, X., Shao, X., Wang, H., Liu, X., Ke, X., et al. (2019). tertButylhydroquinone Treatment Alleviates Contrast-Induced Nephropathy in Rats by Activating the Nrf2/Sirt3/SOD2 Signaling Pathway. Oxidative Med. Cell Longevity 2019, 1-11. doi:10.1155/2019/4657651

Zhou, Y., Xia, L., Yao, W., Han, J., and Wang, G. (2020). Arctiin Antagonizes Triptolide-Induced Hepatotoxicity via Activation of Nrf2 Pathway. Biomed. Res. Int. 2020, 1-10. doi:10.1155/2020/2508952

Zhou, Z., Kandhare, A. D., Kandhare, A. A., and Bodhankar, S. L. (2019). Hesperidin Ameliorates Bleomycin-Induced Experimental Pulmonary Fibrosis via Inhibition of TGF-beta1/Smad3/AMPK and IkappaBalpha/NFkappaB Pathways. EXCLI J. 18, 723-745. doi:10.17179/excli2019-1094

Conflict of Interest: The authors declare that the research was conducted in the absence of any commercial or financial relationships that could be construed as a potential conflict of interest.

Publisher's Note: All claims expressed in this article are solely those of the authors and do not necessarily represent those of their affiliated organizations, or those of the publisher, the editors and the reviewers. Any product that may be evaluated in this article, or claim that may be made by its manufacturer, is not guaranteed or endorsed by the publisher.

Copyright () 2022 Gao, Guo, Yang, Wang, Xia, Gong, Zhang and Yan. This is an open-access article distributed under the terms of the Creative Commons Attribution License (CC BY). The use, distribution or reproduction in other forums is permitted, provided the original author(s) and the copyright owner(s) are credited and that the original publication in this journal is cited, in accordance with accepted academic practice. No use, distribution or reproduction is permitted which does not comply with these terms. 